\title{
COOPERATIVE CONSTRUCTION
}

\section{IN SCHOOLS IN CALIFORNIA}

\author{
A Thesis \\ presented to \\ the Faculty of California Polytechnic Sate University, \\ San Luis Obispo
}

In Partial Fulfillment

of the Requirements for the Degree

Master of Science in Architecture

by

John M. Donley

June 2014 
(C) 2014

John M. Donley

ALL RIGHTS RESERVED 


\section{COMMITTEE MEMBERSHIP}

TITLE:

Cooperative Construction in Schools in California

AUTHOR:

John M. Donley

DATE SUBMITTED: June 2014

COMMITTEE CHAIR: Kevin Dong, PhD.

Professor of Architectural Engineering

California Polytechnic State University

COMMITTEE MEMBER Gregory Starzyk, PhD.

Assistant Professor of Construction Management

California Polytechnic State University

COMMITTEE MEMBER: Will Lichtig

Senior Executive, Boldt Construction

FORMER

COMMITTEE MEMBER: James Doerfler, PhD.

Professor of Architecture

Philadelphia University 


\section{ABSTRACT \\ Cooperative Construction in Schools in California}

John M. Donley

The construction industry has lost efficiency since 1964, while becoming increasingly more litigious. Schools in California can ill afford the time to allow the construction industry time to fully evolve. It may take years or decades to fully improve the efficiency of, and reduce the conflict within the construction industry.

At the same time, the construction industry has developed new processes to improve efficiency and reduce conflict. These processes are beginning to be broadly embraced by the industry. They all contain cooperative elements. Taken together they represent a new organizing principle for the construction industry, cooperative construction.

Also concurrently, a previously little-used provision of the California Education Code allows schools freedom to contract for school construction in nearly any reasonable contractual arrangement they see fit for their project and district needs. As a result, school districts in California have developed a new system of project delivery. They are borrowing from here and there and inventing new tools to make projects work for them. Again, cooperative elements at the hearts of the processes.

Keywords: Cooperation, Construction, Schools, Project Delivery System, Leaseleaseback, Schools 


\section{ACKNOWLEDGMENTS}

Margot McDonald

Interim Head of Architecture, Cal Poly

Thomas Fowler

Head of Graduate Studies, Architecture, Cal Poly

Wasserman, Michael

Capital Program Management

Savidge, William

Office of Public School Construction

North, Susan

North Mediation

Choudhry, Wazi

San Francisco Unified School District

Schultz, Barbara

The Communication Factor

Diede, Brett

Diede Construction

Hartung, Robert

Alternative Delivery Systems

Coop, Leigh

Vacaville Unified School District

Leslie, Bruce

Martinez Unified School District

Kim Scott

Blach Construction
Hopkins, Arlene

Los Angeles USD

Flesner, Neal

Ventura Consulting

Carl Overaa

Overaa Construction

Neal Flesner

Ventura Consulting

James Forrester

Antioch USD

Andrew Lawson

Severson Werson

Dick Cowan

Cowan Construction Services

Michael Muraco

Siemens

James Salmon

Collaborative Constr. Resources

John Nichols

HMC Architects

Jim VanGundy

Fairfield-Suisun USD

Stephen Mc Farland

Oxnard Union School District 


\section{TABLE OF CONTENTS}

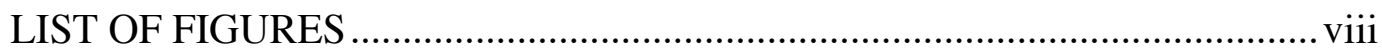

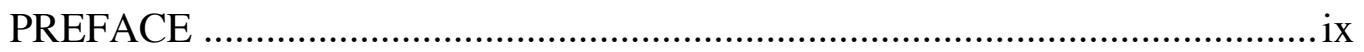

CHAPTER

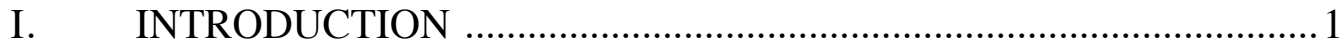

Cooperate, Really Cooperate...................................................... 1

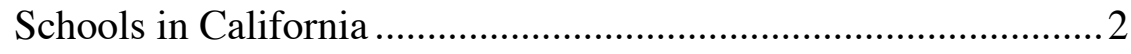

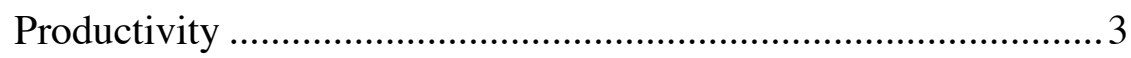

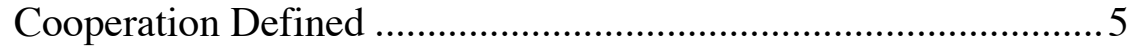

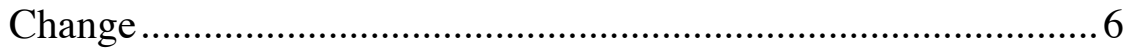

The Way Forward.................................................................

II. SCHOOL FACILITY FUNDING AND PROCEDURES ……............... 9

School Funding Structure ………………………................... 9

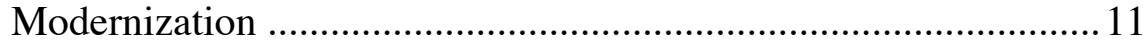

Portable Classrooms ……………………………..................... 14

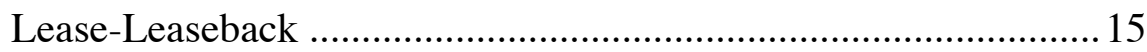

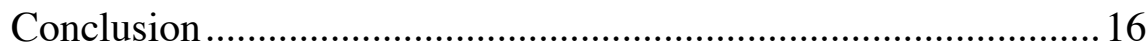

III. COOPERATIVE CONSTRUCTION ..................................................... 18

Brief History of Knowledge Segregation and Integration .............19

Cooperative Construction ………………………….....................2 21

Everybody's Got Skin in the Game .............................................22

How and Why Cooperative Construction Works ..........................22

Evolution of Cooperation..............................................................25

Cooperative Games and Non-Cooperative Games ........................22

The Inner Workings of Cooperation in Construction ....................28

Cooperation and "Winning" ........................................................28

Game Theory Offers Many Confirmations of Cooperation...........29

Mechanics of Game Theory and Construction ……………...........30

Cooperation Summary …………………………………….......... 32

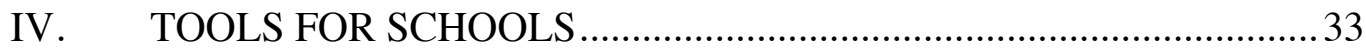

Lease-Leaseback, An Opening for Expansion of Tools ................33

The Two Leases......................................................................... 34

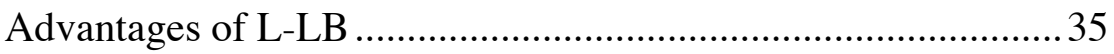

Operation of the Project Under Lease-Leaseback ..........................35

Selection of the Architect and Builder-Developer under Lease-Leaseback .............................................................36

Best Value Procurement Compared to

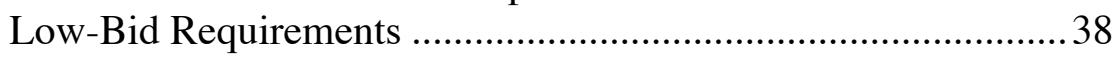

Developing a High Functioning Team for Design Phase .............40

Risk Reduction in "Open Book" and Cost Analysis Processes .......................................................4

Closeout Procedures Under Lease-Leaseback .............................. 43 
A Brief Comparison of Project Delivery under L-LB to Design-Build Delivery Systems ...................... 44

Guaranteed Maximum Price and Contingencies ........................ 44

Green Building and Commissioning ....................................... 45

Dispute Resolution ..........................................................4 46

The Exception that Proves the Rule ...................................... 47

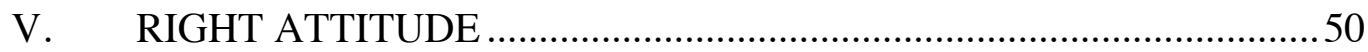

Lean Construction .................................................................50

Partnering .................................................................52

Partnering and Lean are Non-Contractual ...............................54

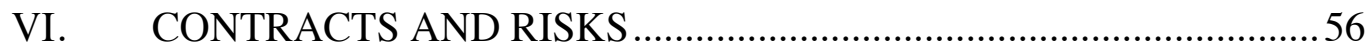

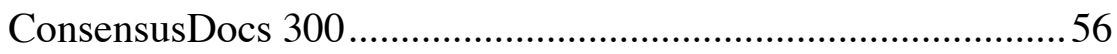

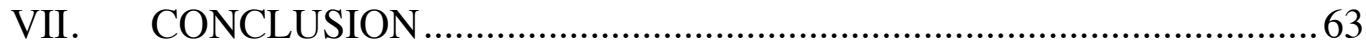

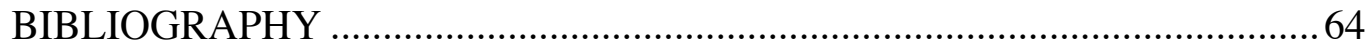

APPENDICES

A. Timeline of School Milestones in Funding and Regulation .............68

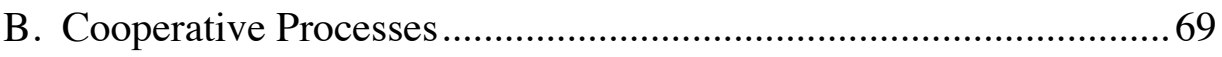

C. Education Code Section 17406 ....................................................... 73

D. Statistics / Costs for the Next Ten Years ....................................... 74

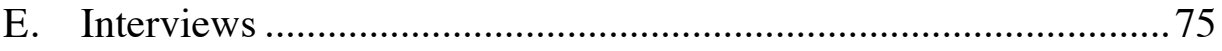

F. Coordination Games, Prisoner's Dilemma and Reputation............ 76

Coordination Games and Non-Coordination Games ................ 76

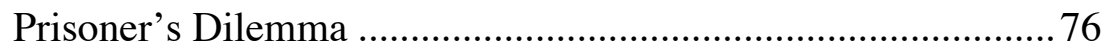

G. ConsensusDocs 300, Selected Portions ....................................... 78

H. Bond Project Martinez USD ..................................................... 100 


\section{LIST OF FIGURES}

Figure

Page

1. Dr. Teicholz's Productivity in Construction Chart, as compared to other industries. 1964 baseline. 4

2. Facility Funding per Pupil: CA versus the U.S. 1998 - 2004.

California is shown in red. The US Average is shown in blue 10

3. Red area is Additions at $23 \%$. Green area is Maintenance at $12 \%$. Blue Area is New Construction at $64 \%$ 12

4. Portable Classrooms have individual HVAC equipment that is widely criticized as unhealthy, wasteful and noisy. 14

5. Knowledge Integration is now possible through BIM 18

6. Alberti designed a predecessor to the camera obscura, a tool for depicting perspective. 20

7. Venn diagram showing 7-set integration. The new construction processes contain cooperative elements in each of them. 22

8. July 2012 Cover of Scientific American about cooperation. 26 


\section{PREFACE}

In 1989, I was employed as an estimator on a new terminal at the San Jose International Airport. I was a newcomer on large projects and wanted to contribute as much as I could.

Shortly after I arrived, the contractor said that the door schedule was hopelessly out of date and they needed to reorder the hardware soon to accommodate changes requested by tenants. The airport contained 480 doors of every imaginable type and hardware group. The door schedule was hand drawn and so full of erasures that the schedule was about $25 \%$ illegible. The architect's team at the site was completely overwhelmed.

The architect's team was overwhelmed because all four of the tenant airlines had changed since the drawings were done and the team had four new tenant improvement designs to incorporate into the main ticketing lobby drawings. The changes for doors went beyond that area and on throughout the airport. Over 200 doors required changes.

I rewrote the list of door types, color, swing, hardware and so forth. I managed to get the door schedule reorganized shortly before the contractor was going to start claiming delay. 
Throughout the two weeks required for the job, people would ask, over and over, why was I doing this. I was amazed at the question because the reason that I was doing it was that it was needed so badly. It didn't matter to me that I was doing what was technically the architect's job. More than once, I heard, "That's not your job." Sometimes it was said in an angry tone. However, I was the only person there with a spreadsheet program capable of managing all the changes needed. Also, I knew doors and hardware from working as a finish carpenter for 15 years. So, for the benefit of the project, it just seemed natural that I would do it. I was just being cooperative.

Soon, the project was completed. For the facility opening, honored guests and the press were invited. Just before the ribbon-cutting ceremony. I noticed a carpenter working on a door, right behind the ceremony location. I walked over to invite him have some food instead of being in the back of the photos of the ceremony. In his hand was the dot-matrix print out from my portable computer and he was using it to install the right hardware on the last door.

One could argue that because of the time spent on the door schedule, some minor adjustments should have been made in the architect's fees or the construction management fees. The point is that reorganizing the door schedule wasn't not my job. Of course it was my job. I was just cooperating by doing what needed to get done. Cooperation is everyone's job. 
Cooperation has long been on my mind. Later, as a Project Manager of a $\$ 38$ million project fraught with difficulties, I attended many contentious meetings after walking past the craftsmen building the project. I would watch them coordinate and cooperate nearly every moment. This felt familiar because when I worked as a craftsman, it was a constant effort to get my work done while fully cooperating with anyone else nearby. There isn't any choice; without cooperation nothing would ever get built. All good craftsmen know this.

While considering making the applications to attend graduate school, I came across the July 2012 issue of Scientific American magazine. The cover article was “The Evolution of Cooperation” by Martin A. Nowak. In the article, Mr. Nowak included a discussion of game theory, a mathematical/psychological construct. The word "cooperation" is a principle concept in Game Theory. Research into game theory and other more recent disciplines has convinced me that cooperation, especially if made into an organizing principle, could be the guide for moving a galactic-sized and glacially-paced industry into the future.

John M. Donley

San Luis Obispo

June, 2014 


\section{CHAPTER I}

\section{Introduction}

\section{Cooperate, Really Cooperate}

The construction industry in 2014 is stuck between innovative and traditional practices. The industry has ample reason to change from some of its traditional practices. The two most glaring problems are extraordinarily poor productivity over nearly 50 years and an unusually litigious business history. ${ }^{1}$ Despite the presence of proven opportunities to address both of these problems, such as "design collaboration,", and "Best Value"” procurement systems, progress is painfully slow. ${ }^{4}$ These new processes all contain "cooperation" as an important element in either the attitude of the participants or as a benefit of adoption of the process. Because of this similarity of these new processes, it is reasonable to group them into an organizing principle ${ }^{5}$. That new organizing principle is cooperation. This thesis proposes that adopting such a new organizing principle will get the construction industry moving away from inefficient and contentious traditional practices and headed toward new, successful ones as promptly as possible.

1 Teicholz, P. "Labor-Productivity declines in the Construction Industry: Causes and Remedies (Another Look)" AECbytes Viewpoint \#67, Mar 2013.

2 Design collaboration is the first value proposition of design-build project delivery systems. The architect, engineers and contractors all collaborate in the design phase. Teicholz concurs. op. cit.

3 "Best value" procurement is an alternative to "low-bid" procurement.

${ }^{4}$ Bongiorni, M. "Why is the US Construction Industry Slow to Embrace New Partnering Agreements for Project Delivery?" University of Cambridge, March 2011 p.8

${ }^{5}$ An organizing principle is a term of art in psychology used to describe the elements of perception. One such organizing principle is similarity. The improvement of the perception of the construction industry is the goal of the use of this organizing principle. 
Ten years ago, The Construction Users Roundtable, a forum for public and private owners of projects, formed a committee to study inefficiency and contentiousness, among other problems. A blue-ribbon committee of 20 senior construction professionals delivered a report containing the following conclusion:

The Committee concluded that the difficulties experienced in typical construction projects... are artifacts of a construction process fraught by lack of cooperation and poor information integration. ${ }^{6}$

These ailments, lack of cooperation and poor integration of information, are the subjects of inquiry of this thesis. In solving these problems, time is of the essence because of the needs of some of the construction markets in California. Years may pass before the productivity gap between the construction industry and other industries is sufficiently reduced. But, as it happens, some important construction markets in California need help immediately. Primary among them is school construction.

\section{Schools in California}

The market explored in this thesis is school construction in California. Ours is a state that desperately needs to see rapid and substantial improvement in the provision of school facilities. Schools constantly need renovation, yet California has very limited funds to spend on modernizing these facilities. Statewide, there is already a backlog of renovation work without funding. If the school construction industry could redefine itself quickly by means of improving its productivity and reducing its litigious inclinations, California schools would substantially benefit as well as the construction industry as a whole.

\footnotetext{
${ }^{6}$ The Architectural/Engineering (AE) Productivity Committee, Construction Users Roundtable, 2004 Report, Collaboration, Integrated Information and the Project Lifecycle in Building Design, Construction and Operation
} 
School facilities in California represent an ideal laboratory for the implementation of cooperative construction techniques. In the last five years, a part of this market has done exactly that: developed its own set of cooperative construction techniques.

The benefit to schools of wide adoption of cooperative construction techniques would be faster, more dependable facilities renovations at lower costs. The benefit to the construction industry would be the revitalization of a large market segment that is currently struggling.

Facilities are important to education. They matter to the children. Delaine Eastin, the controversial, yet insightful, California Secretary of Education 1995-2004 said,

"These kids have been to the Mall, they know when adults are serious about facilities." 7

\section{Productivity}

The construction industry is suffering intense criticism because of its failure to become more productive during the 48 years for which we have records, from 1964 through 2012. The industry has become considerably less productive while every other industry in the country became twice as productive. ${ }^{8}$ Productivity, in this context, means the cost of labor hours per dollar of finished product. Paul Teicholz of Stanford, the author of this watershed study, lists six causes of stagnant labor productivity in construction. The second item on his list is lack of collaboration and risk-averse behavior resulting from competitive bidding. He states:

In many project teams, there is a lack of integration of design and construction, and often-poor collaboration among team members. This leads to risk-averse

7 Delaine Eastin, C.A.S.H. Annual Meeting, 1996, Red Lion Inn, Sacramento, CA

${ }^{8}$ Teicholz, op. cit. p. 1 
behavior as team members try to protect themselves from the impacts of changes caused by errors, omissions and owner modifications. These issues are frequently present on design-bid-build and even design-build projects where some team members submit bids (typically sub-contractors), the low bidders receive awards and then try to benefit from extra work. The results are projects that are over budget, behind schedule, and -- more claims. It is not surprising that labor productivity suffers under these conditions. ${ }^{9}$

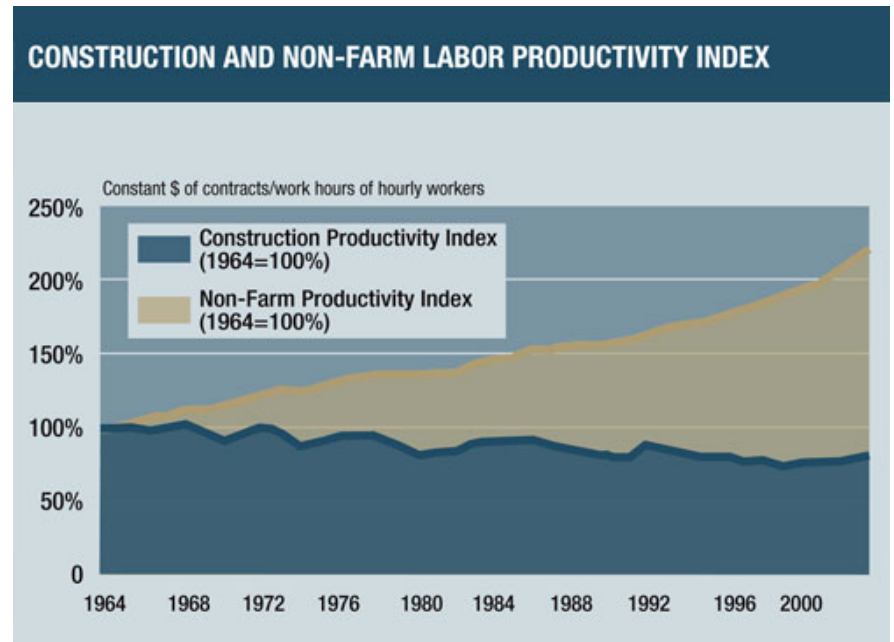

Figure 1, Dr. Teicholz's

Productivity in Construction Chart, as compared to other industries. 1964 baseline.

Dr. Teicholz stirred a revolution in thought within the construction industry. His work is repeatedly cited in books and articles as a supportive argument for changing to increased collaboration in design and coordination of expertise. He cites slow technology adoption along with low interoperability ${ }^{10}$, variation in projects, small firm size and declining wages as additional reasons to expect slow recovery of productivity. The construction industry may never achieve the labor productivity rates of other industries; it is simply too labor-intensive. However Dr. Teicholz feels that the construction industry can improve significantly, if very slowly.

\footnotetext{
${ }^{9}$ Teicholz, op cit. p 6

${ }^{10}$ Interoperability means the ability of one computer program to integrate information with another program. This complex problem is worked on every day by scores of companies and advancements are reported in trade and scholarly journals frequently throughout 2013 and 2014.
} 


\section{Cooperation Defined}

For this paper, "cooperation" includes coordination, collaboration, and knowledge integration. These elements are different and distinct features of cooperation. ${ }^{11}$ When all of these joint efforts are combined, each construction industry professional will have finally recognized and embraced the obvious, daily success of cooperation as practiced by the craftspersons right outside the window of his or her job trailer. All good craftpersons know that cooperation with their peers, as much as possible, is essential to achieving any kind of sustainable production on job sites. For example, temporary power, unstable walking paths, dangerous movement of tools and materials are just a few of the safety challenges that skilled craftspersons face all day. For safety reasons alone, cooperation is a necessity on the job site.

The descriptions by the advocates of each of the cooperative techniques herein (see Appendix B) all include specific references to improved cooperation, often through increased knowledge integration. It is knowledge integration that is both the mechanism for efficiency and the remedy for contentiousness. The professionals know more about their situation through knowledge integration. Their isolation and sense of risk of the unknown is reduced by immersion in the data stream of design collaboration. John Nichols of HMC Architects said, "In collaborative design... one gets smarter decisions from the designer, the contractor, even the owner." 12

11 "Rational Contracting" a similar process, discussed academically and applied in parts of northern Europe in the 1970's arose from similar sentiments and is still used to accomplish a more civilized industry. This thesis is concerned primarily with cost, waste and risk.

12 Nichols, J. Interview, March 15, 2014 
Since 1964, when the data for Dr. Teicholz's productivity study was first collected, the industry now knows much more about design. The industry now knows much more about risk. The industry now knows much more about materials. The industry has more materials. The industry knows much more about dispute resolution than we ever have before. The industry has new methods to address all these elements inherent to construction projects.

Now is the time for the industry to recognize that cooperation is the best organizing principle for its path to a more promising future. Borrowing language from Game Theory ${ }^{13}$ in mathematics, we can define cooperation as always doing what is best for your interests in a project and what is best for the project as a whole.

\section{Change}

Resistance to change is a roadblock. The scope of change that is needed in the construction industry is nothing less than a sea change. Adoption of cooperation is a sea change because it is a transformative change, affecting the approach, performance and outcome of every role in the industry. Unfortunately, change efforts on this magnitude have not been very successful. John Kotter, author of Leading Change (Harvard Business School Press, 1996) studied more than 100 change processes during the 1990s. Many were “...utter failures. Most fall somewhere in between [success and failure] with a distinct tilt toward the lower end of the scale."14

13 See Chapter III, Cooperative Construction

${ }^{14}$ Kotter, J. “Leading Change” 1996 Article Harvard Business School Press, p5 
This thesis doesn't labor under the false impression that a change in the organizing principle of a major industry is going to be smooth, quick or easy. Notwithstanding the difficulty, it is incumbent upon the construction professionals of today to bring our industry into the modern world.

\section{The Way Forward}

Will Lichtig, formerly legal counsel to Sutter Health and currently Senior Executive with Boldt Construction in Sacramento California writes:

Hypothesis: Risk on projects has become so complex and specialization has caused such a disintegration of expertise, that the only real way to truly assess, mange and mitigate risk in the development, design, fabrication and assembly of projects is to "re-integrate" that expertise thru the formation of IPD [Integrated Project Delivery] teams and the development of new processes for design and delivery using BIM [Building Information Modeling] and the project platform. ${ }^{15}$

Cooperation, elevated to an organizing principle of the industry, will accomplish these goals as quickly as possible.

This discussion begins with the analysis of school facilities. Then focus shifts to cooperation itself - and proof of its effectiveness using Game Theory. The discussion proceeds to an unusual opportunity for schools to adopt cooperative construction techniques in new hybrid project delivery system of their own design. A study of the right attitude for cooperative construction follows. It is demonstrated by two well-known techniques: Lean Construction and Partnering. Then follows is a discussion of a sample contracts. Throughout are interviews with today's professionals and how they are using cooperative techniques to achieve their goals.

15 Lichtig, Will. Hypothesis Handwritten message. Nov 2013. 


\section{CHAPTER II}

\section{School Facility Funding And Procedures}

Every school day, 6.5 million people spend their day in a public school in California. This group is equivalent in size to the entire population of Tennessee. This large public resource consists of 10,000 buildings. Generally speaking, the public has voted to approve funds for school facilities frequently, although inconsistently. ${ }^{1}$ The future holds serious questions about funding, the complexity of the type of work needed in schools and the way forward for the construction industry in serving this large market area. But, at the same time, a revitalized system of development (lease-leaseback) has freed the districts from regulations and provided an unprecedented opportunity for improved project delivery. The context of recent history of school funding and procedures shows the background so that the unusual and innovative nature of new project delivery systems can be seen in detail.

\section{School Funding Structure}

California school facilities, viewed together, are a significantly valuable community resource, worthy of great care. And Californians do care about their schools. Californians voted for and authorized over one hundred billion dollars of bond funds for school facilities in bond elections over six years from 1998 to $2004 .^{2}$

\footnotetext{
${ }^{1}$ See Appendix A. Timeline of School Milestones in Funding and Regulations.

${ }^{2}$ See Figure 2 Brunner, E. Financing School Facilities in California, Essay, Quinnipiac University 2011 Camden, Ct. p54
} 
California has a hybrid system of funding for schools. The State allocates funds from voter-approved bonds for school facilities. This money is commonly matched by locally issued, voter-approved bonds. Both county funding and federal funding serve as sources of funding for specific programs, such as special education. Currently, facilities funding is primarily a result of local bond issues. As it turns out, the system operates erratically. The funding system has a long and varied history. (See Appendix A.)

A major bond issue, which would have only partially funded an existing backlog, was

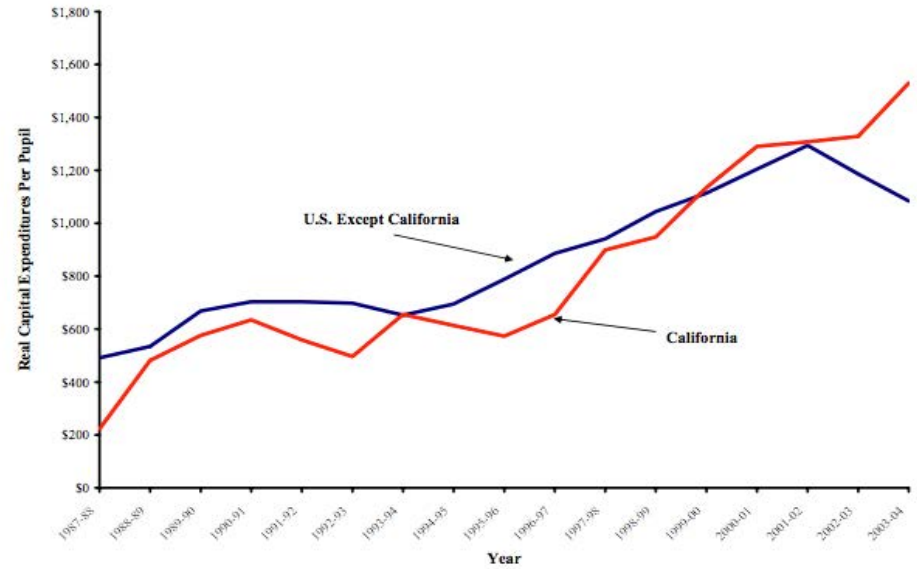

Figure 2. Facility Funding Per Pupil: CA vs. the US 1988-2004. California is shown in red, the US Average is shown in blue. placed on the ballot in June 1994. The measure failed by only $.4 \%$. The school facility professionals spearheaded legislation that reorganized the methods of funding delivery and finally, the November 1998 Ballot contained a bond issue for $\$ 6.7$ billion. It passed with $62 \%$ of the vote. ${ }^{3}$

The period from 1998 through 2004 was the golden age in the statewide funding of school facilities. By 2000, California surpassed the national average in funding of facilities per pupil. ${ }^{4}$ The last of the large statewide bonds passed in 2004.

3 State General Obligation Bond History Department of Education CalEdFacts, Web. Accessed Jan 19, 2014, http://www.cde.ca.gov/ls/fa/sf/cefgobondhistory.asp 


\section{Modernization}

Studies have shown ${ }^{5}$ that California needs to invest another one hundred billion dollars or more over the next ten years into school facilities in California. The history and the present conditions and the need to upgrade the 300,000 public classrooms in California must be summarized very broadly for this thesis.

The types of school projects waiting in line to get started have changed in recent years. To add to the complexity of the upcoming challenges, we have much more modernization work and less new construction to perform than in previous years. Modernization is defined as work on a school that is more than 25 years old. This is over $60 \%$ of the school buildings in the state. ${ }^{6}$ Of the 300,000 existing classrooms, thirty percent (that is $90,000)$ of the classrooms are over 50 years old. Of those, 30,000 are over 70 years old. ${ }^{7}$ These buildings, simply by virtue of their age and variance in levels of maintenance, are, in any case, outdated for modern education. They are not compliant with modern standards for classrooms. The priorities for modernizations are seismic safety, hazardous materials abatement, architectural upgrade, energy efficiency, technology upgrades and deferred maintenance. Over the last 15 years, while the state has invested $\$ 118$ billion in

\footnotetext{
4 Brunner, E. Financing School Facilities in California, Essay, Quinnipiac University 2011 Camden, Ct. p54

${ }^{3}$ Center for Cities and Schools, University of California, School Facilities in California, 2012, Executive Summary p. ii, Web http://citiesandschools.berkeley.edu/reports/CCS2012CAK12facilities.pdf

6 Dept. of Education, Fingertip Facts, 2011, p1 cde.ca.gov

${ }^{7}$ http://citiesandschools.berkeley.edu/reports/CCS2012CAK12facilities.pdf Summary p ii
} 
schools facilities, only $28 \%$ was earmarked for modernization. ${ }^{8} \quad$ At this time we need $50 \%$ of funding to be allocated to modernization.

Total Construction broken into its Components, average for 1987-2007

- sew wort

- edsitions, alseraooss, or reconstruction

- Momenance aed repar

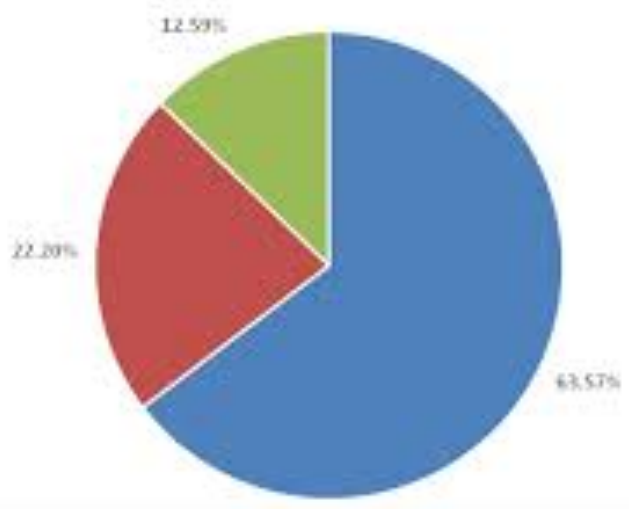

Figure 3. Red area is Additions at $23 \%$.

Green area is Maintenance at $12 \%$ Blue area is New Construction at 64\%.
Appendix $\mathrm{H}$ is a letter from Bruce

Leslie of Martinez Unified School

District. Mr. Leslie shows a list of completed and planned projects funded by local bond issues. This list contains many common modernization projects. Mr. Leslie also describes the project leadership group and some project procedures.

In AECBytes.com, Viewpoint Newsletter, March 2013, Professor

Paul Teicholz updated his seminal 2004 article with nine more years of data. ${ }^{9}$ The newer data showed continuing trends of labor inefficiency in construction as compared to other industries. Central to this problem is that much of the work of the construction industry is comprised of additions, alterations, reconstruction, maintenance or repair. His analysis from 1987 to 2007 shows modernization needs to represent about $35 \%$ of the industry nationwide.

\footnotetext{
8 Department of Finance, Office of Public School Construction, Strategic Growth Plan, Bond Accountability Summaries. California Agency publication. 1998 - 2006. www.opsc.dgs.ca.gov/bondaca

9 Teicholz, op. cit. Also, Figure 3.
} 
In California schools, since modernization will represent an even greater percentage of work needed, the districts and the industry will need yet more robust cost controls and budget analysis during planning, as provided by new "design-assist" techniques. See Chapter IV, Tools for Schools. Modernization is commonly thought of as more unpredictable than new construction because of the element of more "reasonably unforeseen" conditions arise more in an existing building than a new one.

There is a compelling example of how modernization can be improved significantly using inventive cooperative techniques. Additional information exchange, such as detailed reports of existing conditions and carefully organized phasing programs, all prearranged with the schools faculty, were provided to bidders for modernizations in San Francisco Unified School District. The SFUSD obtained excellent results with this substantially increased information exchange in a bidding process. See Chapter IV, Tools for Schools, The Exception That Proves the Rule. During the last few years, the need for new facilities, as well as for modernization, has mounted again. ${ }^{10}$ A study from UC Berkeley's Center for Cities and Schools was presented in August 2012 to Senate Education Subcommittee on Sustainable School Facilities. ${ }^{11}$ At that time, modernizationfunding requests were $\$ 100$ million over available funds. Up through April 7, 2014, the

10 "Hearing Summary: California's K-12 Educational Infrastructure Investments." C.A.S.H. Register August 2012. Print. Growth is localized with some districts growing very quickly.

11 Vincent, Jeffrey. California's K-12 Educational Infrastructure Investments: Leveraging the State's Role for Quality School Facilities in Sustainable Communities. 2012, Berkeley: Center for Cities and Schools, University of California. 
unfunded modernization projects before the State Allocation Board add up to

$\$ 217,000,000 .^{12}$

\section{Portable Classrooms}

Of the approximately 300,000 classrooms in California, 75,000 are portable classrooms. ${ }^{13}$ 2 million students attend classes in these buildings every school day in California. ${ }^{14} 1998$ legislation limited portable classrooms to a maximum of $25 \%$ of all classrooms. (Prior to 1998, 30\% of new classrooms were required to be portables. ) There has been little

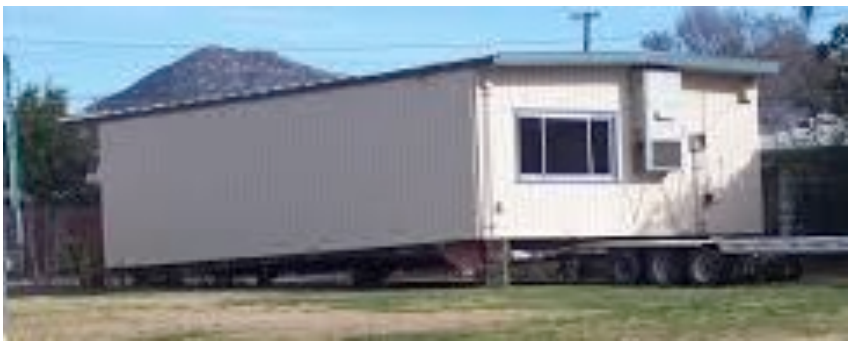

Figure 4. Portable Classrooms have individual HVAC equipment that is widely criticized as unhealthy, wasteful and noisy. reduction in 16 years in the number

of portables. Criticisms of portable

classrooms in California include

unhealthy ventilation, energy waste and noisy classrooms. ${ }^{15}$ Portable classrooms need significantly more

maintenance and repair than permanent buildings.

12 State Allocation Board, Unfunded Modernization Projects, http://www.documents.dgs.ca.gov/OPSC/Resources/Unf_Lst.pdf

${ }^{13}$ A study in 2004 , found that $40 \%$ of the portable schools ventilation systems supplied inadequate fresh air exchange, (CO level $>1000 \mathrm{ppm}$ ) and that $10 \%$ of the schools had severely inadequate air exchange (CO level > 2000 ppm) Sixty percent of the teachers turned off air conditioners at times due to noise of poor quality units. California Department of Health Services, "Environmental Health Conditions in California's Portable Classrooms." Novembar 2004. http://www.arb.ca.gov/research/apr/reports/l3006.pdf 14 Toward cooler, quieter, energy-efficient portable classrooms" Lawrence Berkeley Lab, Science Beat Newsletter, August 2002. http://www2.lbl.gov/ScienceArticles/Archive/EETD-portable-classrooms.html 15 California Air Resources Board, op cit, p 17 
Portables were originally intended to provide temporary housing for fluctuating school district enrollments. The quality varies substantially between different manufacturers. The level of maintenance varies between school districts.

The Chief Investigator for a Lawrence Berkeley Lab report said that "you can design [portable] buildings that use less energy and address indoor air quality issues, if you do it right and are clever about it."16 The point here is that these buildings are portable and temporary, not less expensive solutions to housing students and staff permanently. From a long-term point of view, there is extra cost in maintaining these temporary buildings for extended periods. HMC Architects report in Nov. 2011 shows that the Santa Anna Unified School District reduced its inventory of 768 aging portable classrooms to less than 100 at a maintenance savings of nearly $\$ 2,000,000$ per year. ${ }^{17}$

\section{Lease-Leaseback}

These problems of increased proportion of modernization projects, aging facilities, thousands of left-over portable classrooms and an existing backlog of projects needing statewide funding present an urgent need for a new approach toward the provision of construction services for schools in California. It is possible that a new development technique may address these problems and is already underway. In the last few years, a development has recently expanded choices for districts regarding facilities provision under the Education Code. This fast-growing process has to do with how we fund and

16 "Toward cooler, quieter, energy-efficient portable classrooms" Lawrence Berkeley Lab, Science Beat Newsletter, August 2002. Print.

17 HMC Architects, November 9, 2011 Blog, Web http://blog.hmcarchitects.com/aging-portable-classrooms-santa-anas-replacementplan-to-save-dollars/ 
procure school facilities. In 1957, the legislature passed the "Lease-Leaseback" (L-LB) development system for schools. The process has recently been revived and has been tested and validated in the courts. Counsel for Los Alamitos Unified School District published the following news release:

the lease-leaseback construction delivery method is a State-recognized tried and true method which can foster a more collaborative approach between district owner, contractors and architects. ${ }^{18}$

This is an unusual method of exchanging leases to facilitate the construction of a school while the property is leased to the builder. Please note that L-LB is a development system. It is not, in and of itself, a project delivery system. A development system is a method of funding through public bond issues and associated rules regarding the use of the proceeds from the bond sales.

In a presentation before the Coalition for Adequate School Housing, (C.A.S.H.) in February 2006, Paula De Sousa, a senior attorney with Best, Best and Krieger in Sacramento, reported an advantage of Lease-Leaseback, saying that it, "Allows for the architect, contractor and District to be on the same team." 19

\section{Conclusion}

The preferred procurement system for schools in California is now well aligned with cooperative approaches toward project delivery. Chapter IV, Tools for Schools goes into

${ }^{18}$ Chialtas, Andreas. Court Validates Use of Lease-Leaseback Construction Contracts for School Districts Atkinson, Andelson, Loya, Ruud \& Romo, News Release, June 25, 2013. Cerritos, CA.

19 DeSousa, P. Lease-Leaseback 2005 - A Whole New Ball Game? C.A.S.H. 26 ${ }^{\text {th }}$ Annual Conference on School Facilities. p.20 
detail about how school facilities professionals are creating their own cooperative project delivery systems under L-LB programs. Chapter 3 discusses the concepts of cooperation and cooperative construction. Chapter 3 also provides a metric to evaluate the power of these concepts: Game Theory. 


\section{CHAPTER III}

\section{Cooperative Construction}

Cooperation can be expanded to a new level using techniques begun in the last decade but not yet widely adopted throughout the construction industry. The development of increased communication and planning capability through electronics has created an opportunity to integrate knowledge and expand cooperation exponentially.

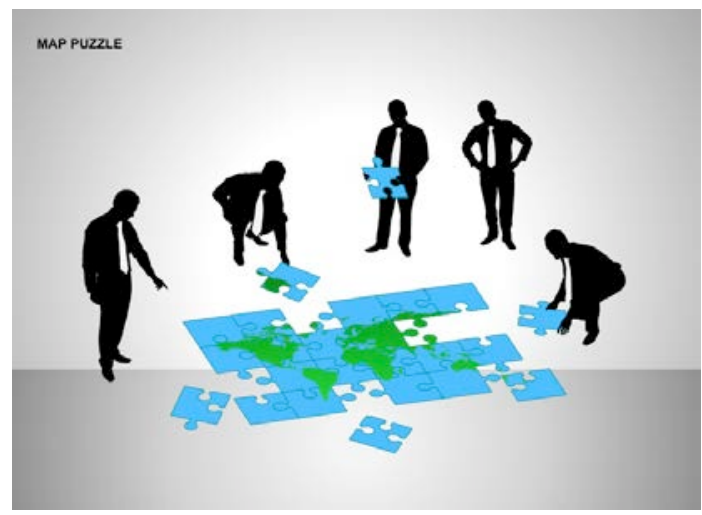

Figure 5. Knowledge Integration is now possible through BIM.
As said before, "cooperation" in this thesis means coordination, collaboration and knowledge integration. This thesis proposes an ethos of cooperation. Such an ethos is guided by taking action in one's own best interests and in the best interests of the project as a whole.

Knowledge integration is the successful reduction of divisions along lines of expertise as pointed out by Will Lichtig. Specialization, to some degree, must occur. Each specialty has knowledge unique to its own discipline. Knowledge integration occurs when salient details are shared, often through an electronic design portal, in the actual design. For example, the byzantine process of "shop drawings" can now be replaced by allowing the mechanical engineer and the mechanical subcontractor direct access to the design program. The traditional method of providing the detail of, for example, steel fabrication is to have the fabricator provide drawings after the design is complete and the bid is 
awarded. In this old method, the bid is based on a well-educated guess; the means and methods of construction is negotiated during the first few weeks of the project. Months have already been wasted. Design collaboration includes developing the steel details during the design phase. Off site fabrication of additional project assemblies can be developed, saving time and money. This is the promise of BIM, in a new ethos of cooperation.

Knowledge integration in the design phase is the highest aspiration of cooperative construction. The designs for modern schools are of sufficient complexity that we need to capture the information efficiently from the professionals engaged on the project. With BIM this is accomplished. The waste inherent in incomplete designs will be eliminated, increasing efficiency and reducing contentiousness.

\section{Brief History of Knowledge Segregation and Integration}

Dr. Barbara Jackson gives us a historical perspective of project complexity in DesignBuild Essentials.

...all the pieces of the design and construction puzzle were stored [before the Renaissance] in a single location - in the Master Builder's brain, providing single source accountability without the complications of contradicting agendas and independent special interests. ${ }^{1}$

Over 400 years later, there exists a single location where all the pieces of the construction puzzle can be stored instead of the Master Builder's brain and that is the design-builder's computer. Computer-aided design and Building Information Modeling (BIM) can finally

\footnotetext{
${ }^{1}$ Jackson, B. Design-Build Essentials, 2011, Delmar Cengage Learning, Clifton Park, New York p. 4
} 
store the design process and allow for designers and builders to work together, multiplying their individual capabilities.

The historical events surrounding the birth of modern Western architecture during the Renaissance are worthy of examination, lest errors are made in the re-integration of knowledge necessary in modern times.

According to the Authors of Design-Build, Planning Through Development, ${ }^{2}$ the development of Architecture as a profession is attributable to Leon Battista Alberti (1404 -

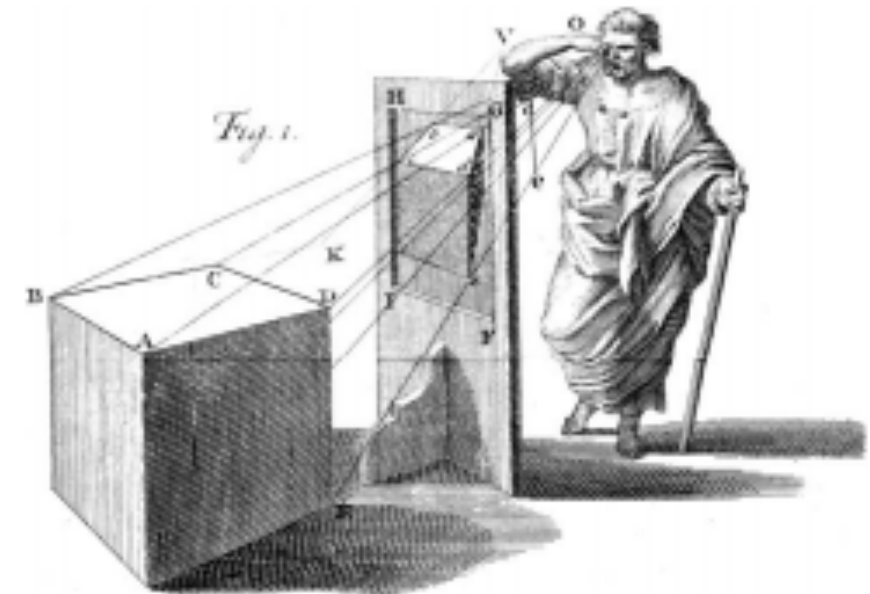

Fig 6. Alberti designed a predecessor of the camera obscura, a tool for depicting perspective.
1472) because he wanted to provide a design for the Santa Maria Novella cathedral in Florence by using drawings and models rather than attending the construction site. ${ }^{3}$ The authors go on to say that this approach leads to the segregation of expertise,

which is so troublesome today.

After considerable study into Alberti's life, it seems reasonable to suggest that he was simply interested in design and the proper attitude of the designer toward aesthetics. ${ }^{4}$ By

2 Beard, J. Loulakis, M. Wundram, E. Design-Build: Planning Through Development McGraw-Hill, New York, 2011, p.14

${ }^{3}$ Alberti traveled to Rome often and served under the "Humanist" Pope, Nicholas V

4 Alberti, L. On Painting. 1436 
designing with great care and then delegating fabrication of skilled others, Alberti - a true polymath - was free to pursue painting, cryptography, athletics and theology. Alberti contributed to many designs of cathedrals, residences and other projects, often collaborating with other designers. His hallmark was integrating his knowledge and his elaborate study of aesthetics with those of other Florentine designers.

The segregation of expertise and knowledge which has arisen since the Renaissance happened because of the increasing complexity of built environment, not because of Alberti's pursuit of excellence in multiple disciplines. The re-integration of expertise, as called for by Mr. Lichtig in Chapter I, is not likely to arise from the rebirth of master builders, such as those who preceded Alberti, but through leadership of cooperative teams using techniques such as BIM and embracing cooperation as a guiding principle.

\section{Cooperative Construction}

Cooperative construction, as discussed herein, is proposed as a "cafeteria" approach. It contains many major concepts ${ }^{5}$ and offers for a structure of a cooperative construction project. No one tool will solve the complexity of a modern school. Rather it will requite the right combination of tools, driven by a unifying principle of cooperation, will predictably improve the production of thousands of complex projects needed across every community in California . Cooperation, as an organizing principle that will guide the construction industry to rid itself of its inefficiency and litigious tendencies.

${ }^{5}$ See Appendix B, Cooperative Processes. 


\section{Everybody's Got Skin in the Game}

The overarching concept for cooperative construction is that all project participants are intertwined in one project. The success of any one participant depends on the success of the project and vise versa. Wrong-headed business concepts that separate interests into

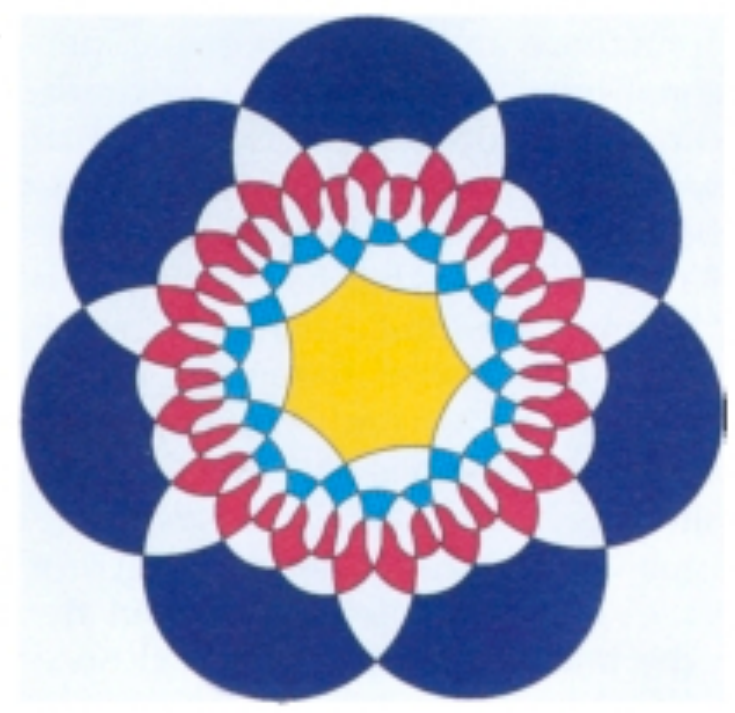

Figure 7. A Venn diagram showing 7-set integration The new construction processes contain cooperative elements in each of them. profit measures for some, yet not

all, are to be avoided. Operational

concepts that divide expertise into

"silos" are to be avoided. Personal

behavior that disrespects contribu-

tions of others is to be avoided.

Dick Bayer, Executive Director of

the Lean Construction Institute

says, "Construction projects, in

order to maximize the project

need to be thought of as collective

enterprises. We all fail when one

fails. " 6

As previously stated, a cooperative approach to an issue means finding the best solution for one's own self-interest and the interest of the project. It is presumed each party is acting in his or her own self-interest, because of basic rationality. "Cooperation" therefore, distills to, "action by each participant in the best interest of the project."

6 The Military Engineer, Article, Leader Profile, Dick Bayer, July 2013, Vol. 105, Number 684, p. 42

http://www.leanconstruction.org/media/docs/Dick_Bayer_LCI_Article.pdf 


\section{How and Why Cooperative Construction Works}

Why engage in cooperative construction as compared to other development and delivery protocols?

1. Cooperation saves money. For example, our common investments in public works are less expensive. Professionals can earn a living out of generating improved productivity, less waste and producing more value.

2. Waste is eliminated where possible. Utilizing Lean Construction, a core cooperative technique, the entire construction industry consumes fewer resources and cuts substantial waste from the economy. Lean Construction is the quintessential cooperative construction technique. Greg Howell, of the Lean Construction Institute defines Lean Construction as "a continuing effort to eliminate waste from a production system to produce ever more value to the customer."

3. Construction time is reduced. This means that neighboring properties are impacted for shorter periods. Financing interest costs are reduced . Insurance policies are shortened. Time-driven General Conditions expenses are saved. Productive properties generate tax revenue sooner. Construction is so disruptive that England, for example, has an organization to minimize the impact on the adjacent properties. ${ }^{8}$ The Design-Build Institute of America, (DBIA) as an example of

\footnotetext{
${ }^{7}$ Howell, G. "Lean Construction Opportunities, Ideas, Practices." Speech at Lean Construction Institute Workshop, Seattle, WA, Sept 2008.

8 The "Considerate Constructors Scheme" was developed as a non-profit by the Construction Industry in the UK in 1997. In 2002, I saw a fellow wearing a tie, directing traffic in London at a construction site entrance, behind him were the "CCS" standards posted on the site fence.
} 
time savings, reports $30 \%$ improvement over design-bid-build project delivery. ${ }^{9}$ Design-Build is a cooperative process because the design collaboration is a primary element of the D-B delivery system.

4. Design is made prominent in the process. The design goes deeper. The design becomes true project planning. Waste is reduced by better, more integrated planning. For example, shop drawings are made irrelevant; they are already in the design. Uncertainty is reduced. Fewer change orders are written. Risk is reduced. Engaging both the designers and the "makers," the creative power of a design is protected and constructability is integrated. The creative elements of the design can be priced as they are being developed, reducing possibilities of late cuts in scope.

5. Cost information, budgeting and modeling can be developed at the conceptual design stage. Fewer changes are needed later in the project. Traditionally, errors in bidding and incomplete designs are both prominent in construction disputes. These are reduced by good design collaboration. Cost risk is reduced even further by projects that utilize Target Value Design, a Lean Construction technique, where the budget controls the design..$^{10}$

6. Quality is more precise. The project drawings include the actual products (for example, heating, ventilating and cooling [HVAC] equipment.) These are precisely matched to the drawings, because the HVAC contractor has been involved in the design. BIM is utilized effectively in design-assist to record and track the input of

9 Federal Highway Administration, Design-Build Effectiveness Study, Jan 2006, p 10. 10 “Target-Value Design: Nine Foundational Practices for Delivering Surprising Client Value" Lean Project Consulting, Inc. 2007 www.leanproject.com 
materials, products, processes normally shown only in specifications books. "Or equal" language in specifications is not needed. The design has already been developed to include the correct materials in coordination with the builder.

7. Risk and cost are reduced. New processes such as decision trees and Dispute Review Boards (DRB) will reduce litigation significantly. In a seminar recently, Ferdi Fourie, ${ }^{11}$ a claims administrator from Kiewit Construction, said that he receives approvals for discounted proposals from firm owners when a DRB is employed. Decision trees and Dispute Review Boards are a cooperative process because disputes are resolved quickly in the best interest of the project, while the individual company releases rights to go directly to litigation. The mitigation processes must be prepared for in advance, for example in ConsensusDocs 300 Article 4.6, see Chapter VI, Contracts and Risks.

\section{Evolution of Cooperation}

The cover of the July 2012 Scientific American has a drawing of a person's head in cross-section. The brain is made of dancers in smooth blue-grey costumes creating a brain made of other people. The artwork displays the thrust of the article: cooperation means holding a concern about others. "Humans help other humans do everything." The cover article is "The Evolution of Cooperation."12 This article, with a rich scientific core, was written by Martin Nowak, professor of biology and mathematics at Harvard.

\footnotetext{
${ }_{11} \mathrm{Mr}$. Fourie is also a visiting Professor at Virginia Tech. Mr. Fourie was quoted from the 2013 Construction Superconference, December 2013, Palace Hotel, San Francisco, CA.

12 This article was the genesis of the the author's research into Game Theory. Two other sources are the main research sources for this section of the thesis. They are:
} 
His thesis shows cooperation from an additional angle. Nowak shows how cooperation is much more than a concern for others. He asserts that cooperation is profitable.

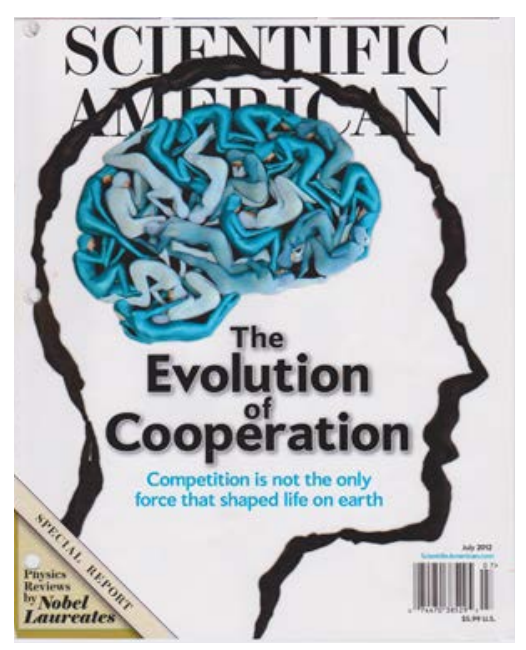

Figure 8 July 2012 Cover of Scientific American about cooperation.
This thesis' abstract asserts that all can benefit from cooperation inside the construction industry, even though cooperation sometimes appears in tension with the natural tendency towards self-interest.

The foundation of Nowak's article utilizes Game Theory as proof of cooperation's success. There are numerous benefits attributable to cooperative behavior that is demonstrated by Game Theory. The language available in this - mostly mathematical - discipline is useful to

describe each participant and their strategies.

Nowak's article reports that many species of animals display cooperative behavior and many species flourish because of their cooperative nature - none more than humans. In cooperative behavior, the self-interest of rational humans is maintained in simultaneous balance with the interests of others. Human interactions that display cooperation have been widely analyzed and measured Game Theory.

In Game Theory, all human interactions are discussed as "games." This thesis will use the rubric of Game Theory for discussing the behavior of principals while executing construction contracts. Scholarly research in Game Theory gives us the language to

The Evolution of Cooperation, Robert Axelrod, Basic Books, New York, 1984, and "Economics 159," Benjamin Polak, Open Yale Courses, 2010, http://oyc.yale.edu/economica/econ-159/lecture-1 
discuss the details of commonplace behaviors. We will use this language to discuss the duties of professionals in construction projects.

\section{Cooperative Games and Non-Cooperative Games}

First, the world of Game Theory divides games into cooperative and non-cooperative games. These are terms of art. For example, "non-cooperative" game does not mean an uncooperative game. A cooperative game is one in which the participants agree to a set of rules and, for purposes of analysis, faithfully follow them. A non-cooperative game is simply a game that does not contain predetermined rules. The process of creating a cooperative game is negotiation. The conclusion of the negotiation is the point when each participant can no longer improve his or her position without some change in the position of one of the other participants.

At this point, the players have arrived at Nash's Equilibrium. The famous mathematician and Nobel Prize winner, John Nash, analyzed this point in human interaction and gave it the name "equilibrium." In construction, Nash's Equilibrium is when the pen hits the contract. At the point of Nash's Equilibrium, the participants can "cooperate" (agree to proceed) or "defect" (decline to participate.) The parties have discussed the contract, understood the proposal and negotiated the best position possible. Furthermore, each fully understands the positions of the other parties. All possible information has been exchanged, so they can now enter into an agreement under a set of rules. When they choose to cooperate, they are entering into a cooperative game by simply agreeing to the rules. With his findings, John Nash reoriented the focus of business interactions in hundreds of industries around the world. In modern construction, the process occurs repeatedly. The conclusion of a negotiation and execution of an agreement happens many 
times during any one contract for any project. Every change order negotiation, every update of a schedule, every payment contains a new opportunity for negotiation, equilibrium, and cooperating under the rules.

This analysis is a condensation of an elaborate mathematical theory. The primary functions inside Game Theory are worth reviewing in detail because they give us a detailed language for discussing of cooperation in construction.

\section{The Inner Workings of Cooperation in Construction}

A construction contract, then, is a series of cooperative games. At any point, a party can choose to cooperate or not. Defection can happen in a smaller negotiation inside the contract without voiding the overall agreement. The purpose of proposing a new ethos of behavior inside the contract is to increase the speed and success of re-enacting the process of agreement numerous times. At its most basic, finding equilibrium quickly is the main job of the new construction professional. It is not to maximize the profit for themselves, or shift the risk to another party; it is to find the equilibrium point of hundreds of negotiations as quickly as possible. Defections of one party or another in any interaction within a construction project can delay a project - rarely an acceptable outcome. The rules of the new processes described in Appendix B, give construction professionals paths to avoid the antiquated practices of risk-shifting and price manipulations, by recognizing their wastefulness and consigning them to the dustbin.

\section{Cooperation and "Winning"}

There is proof that cooperation can be a dominant strategy. It is contained inside Game Theory. This theory helps to show when, how, and why cooperation wins. Cooperation 
is the best outcome in any interaction because, rational participants find the best outcome for themselves and for the project. Winning means a cooperative kind of winning. Winning means a sustainable kind of winning. Winning inside the principle of cooperative construction is a kind of outcome that one can do over and over again. It is this simple fact, the repetition of encounters, sometimes for years, of construction professionals that both promote and stabilize cooperative behavior. Robert Axelrod states: "For cooperation to prove stable, the future must have a sufficiently large shadow." 13 The indefinite number of interactions that arise on a construction project is one of the most stabilizing factors for cooperative behavior.

\section{Game Theory Offers Many Confirmations of Cooperation}

There are five ways that game theory shows the utility of cooperation as a strategy in business interactions, particularly as applied to the construction industry.

1. Nash's Equilibrium: This is the point at which no one participant in a negotiation can improve his or her strategy, given the strategy of the other participants. All negotiations tend to move toward Nash's Equilibrium. The participants are presumed to be interested in their own best outcome while simultaneously finding the best outcome for the group.

2. No Regrets: When Nash's Equilibrium is established, the system of confirmation and execution of process begins with an internal processing of the results of the negotiation. Each participant looks for regrets; when none are found, then all parties are ready for a new interaction. Fundamental to Game Theory is rationality

${ }^{13}$ Axelrod, R. op. cit. p. 4 
of the participants. Therefore all participants are expected to decline an agreement that will cause them to carry regrets.

3. Tit for Tat: This is the winning strategy in the most studied game in all of Game Theory: Prisoner's Dilemma. ${ }^{14}$ When the game is played in rounds and it is called Iterated Prisoners Dilemma. The most successful strategy is to start cooperatively, then respond to the other player. (See Appendix F, Prisoner's Dilemma.) The lesson learned is that cooperation begets cooperation.

4. Strategic Thinking: A good negotiator places himself in the other person's shoes, viewing that persons strategies from his or her point of view. One person's response must always be the best response in terms of the other's responses.

5. Leadership: In coordination games (or any interaction where communication is available) leadership can assist in finding Nash's Equilibrium. The expectation that other participants act cooperatively will increase the likelihood that all will in fact do so. Good leadership can promote and effectively increase cooperative behavior by predicting it. The leadership findings in Game Theory have importance for the construction industry.

\section{Mechanics of Game Theory and Construction}

What do we take from game theory and apply toward construction? Game theory proves for us that cooperation is applicable to the construction industry in two specific ways, both useful:

1. Coordination Games: A construction project would fall under the category of a "coordination game" (one where external standards apply, such as building

${ }^{14}$ Axelrod, R. op. cit. p 53. See Appendix F, Prisoner's Dilemma. 
codes.) In coordination games,${ }^{15}$ communication can help produce a cooperative interaction. For example, clear communication regarding the compliance with Building Codes is to everyone's advantage. A coordination game arises from a situation where all parties can realize mutual gains, but only through consistent decisions. Therefore the role of communication is paramount. A leader can inquire, advocate, ask for consensus and lead the discussion to equilibrium quickly, leaving everyone with no regrets. The strength of a leader's conviction about cooperative processes is predictive of success. This is the duty of leadership.

2. Games that are not Coordination Games: Other cooperative (not coordination) games do not provide for communication and do not adhere to a set of external standards. The parties can only "communicate" indirectly by interpreting one another's moves and strategize accordingly. This is the role of reputation, a term of art in Game Theory, and reputation is always a dominant element in interactions in construction. These non-coordinated interactions occur often under the awesome press of time in construction. For example, one may need to make commitments, without having time to obtain all of the information about an issue. Using cooperation as a dominant, repeating strategy, (just the way we see that "Tit of Tat" works in the Prisoner's Dilemma, see Appendix F.) reputation can be used to gain the necessary time to achieve a successful result.

15 Coordination Games have a maximum "payoff" when the players have matching strategies, such as compliance with external standards. 
In a coordination game leadership communication can increase the success of finding equilibrium through simply predicting it. In a non-coordination game, where communication is limited or not available, reputation becomes the key to finding equilibrium. Either way, through leadership or reputation, today's professionals must bring the right attitude to the project to move the construction industry forward. See Chapter V, Right Attitude.

\section{Cooperation Summary}

Our industry creates some of the largest, most expensive products known to our species. The scale of things at hand amplifies perception of risk on any given day. The relentless pressure to finish the construction as soon as possible adds to the sense of risk because any delay can become a source of criticism. These simple facts influence how the participants behave in decision-making. Cooperation can affect the behavior of participants and the outcome of the project for the better.

The complex design and building process is such an elaborate exercise that the demonstrable positive effects of cooperation are necessary to advance the construction industry beyond its current difficulties. The repeated nature of the interactions of parties brings reputation into play, even when communication is limited by the press of time. A highly skilled leader can make any almost situation work. While attempting to provide the best choices possible for the project principals, their leadership skills can prevail in cooperatively guiding each other to the best solution for the project and for themselves. 


\section{CHAPTER IV}

\section{Tools For Schools}

Many modern cooperative construction techniques are in place in school construction as of 2014. These are cooperative processes that have achieved positive track records over the last ten years. However, the coordination and further expansion of these techniques into school construction has yet to be accomplished on a scale necessary to keep up with the workflow of facilities in California. School Districts are currently developing their own systems to best suit their needs and the open regulatory structure available to them. Starting with a detailed review of Lease-Leaseback (L-LB) and its impact on school facilities, there are brief reviews of other highly important cooperative tools and how they fit into L-LB. The cooperative techniques to be described below are:

1. Best Value Procurement

2. Building Information Modeling (BIM)

3. Design-Assist, Design-Build programs and Cost Modeling.

4. Guaranteed Maximum Pricing (GMP) and Project Target Cost Estimating (PTCE)

5. Green Building and Commissioning

6. Dispute Review Boards

\section{Lease-Leaseback, An Opening for Expansion of Tools.}

The Lease-leaseback, (L-LB) system is not a project delivery system. Rather, it is a method of developing school facilities. The distinction is that under L-LB, the district can use any project delivery system. L-LB is a system of leases that allows the district to develop property into a school, or modernize a school, when the district is paying for the project through leaseback payments instead of construction contract payments. There are fewer regulations in this system. 
After identifying a need for capital improvements, the district can propose issuing General Obligation (G.O.) bonds and, given voter approval of 55\% or more, sell the bonds and utilize the funds to purchase property and fund the development. All of the standard regulations from the Department of Finance apply to the G.O. bonds. For example, an oversight committee must be formed to follow the use of the income from the bond sale, and the committee must regularly and publicly report to the district board. However, under L-LB, these are the main requirements placed upon the district.

The district can lease property that they own to a developer-builder to construct or modernize a facility, then lease back the completed facility. The L-LB system has been confirmed in courts as well as by actions of the governor's office. It's now a growing practice in school districts today. Mike Wasserman, senior consultant for Capitol Program Management recently said, "Lease-Leaseback is the best delivery method for most projects in my opinion."

\section{The Two Leases}

Under L-LB, here are two leases:

1. Site Lease: The district leases a school site to a builder and provides completed plans. The lease contains a provision requiring the construction of a school with a guaranteed maximum price and a completion date. Commonly, the builder has worked with the district previously and has participated in the design of the facility to be built.

2. Facilities Lease: The district leases back the completed facility with payments reflecting the value of the new building. The lease payments are similar to construction

${ }^{1}$ Michael Wasserman, Principal, Capital Program Management, January 2014 
payments. The district, using funding from local and statewide bonds, obtains ownership of the facility as the payments are made.

\section{Advantages of L-LB}

Under lease-leaseback, in California schools, a district can utilize any project delivery system currently in use today or, as it turns out, add, change and modify existing project delivery systems. The L-LB system is complex, yet it is less complex than other procurement systems that are allowed under existing legislation in California. This is understandably why the Assistant Director of the Office of Public School Construction, Michael Savidge, reports that all of the Design-Build projects in schools are being built under lease-leaseback funding programs because there is less regulation and reporting.

Under L-LB, the regulations regarding the operation of a school construction project, consisting of hundreds of pages, are set aside and only two paragraphs, Education Code $\# 17406,{ }^{2}$ control the district's actions regarding the construction and use of the public funds. Other regulations in other sections of state codes that continue to apply are the basic structural safety regulation of the Field Act of 1933, the California Building Code, applicable labor laws and the Department of Finance rules.

\section{Operation of the Project Under Lease-Leaseback}

It tells us a lot about cooperative construction techniques to look in detail into a new hybrid project delivery system (this project delivery system does not have a name as of yet) which uses L-LB. Since many regulations about how to organize and build a project can be set aside, districts have created a system of their own design of project delivery.

\footnotetext{
${ }^{2}$ See Appendix C.
} 
The districts utilizing these new procedures under L-LB are quite sophisticated owners, with development staff and well-informed boards of directors. There are many sources where a district can learn about L-LB, but the district must go there to obtain the information. An experienced attorney is required to draw up the leases. There are descriptive papers published on the net or consultants who know how the most popular new system is being used. The organization C.A.S.H. has regular seminars on these development procedures. ${ }^{3}$ Kim Scott of Blach Construction has studied project delivery systems along with the principals of her firm and they supply information to their clients re: $\mathrm{L}-\mathrm{LB}^{4}$

Since the popularization of L-LB recently, a hybrid method of project delivery has grown up. It was created organically out of the conditions of the development scheme. This hybrid project management system, assembled by the best minds available, is really a collection of cooperative construction techniques with a number of variations selected to provide efficiency, reduce contentiousness and share risk for each project. One possible name might be "Balanced Project Delivery."

\section{Selection of Architect and Builder-Developer under Lease-Leaseback}

Let us look at a school facilities project chronologically so that the details of this new project delivery system can be discussed in detail. After passing a bond election, a District first decides on the builder-developer and the architect. According to Mike Wasserman, a principal in Capitol Project Management, a qualifications-based selection

${ }^{3}$ C.A.S.H. Seminar Schedule Coalition for Adequate School Housing, 2011. Web. dshttp://www.cashnet.org/meetings/2011_Annual_Conference/TuesdayFebruary2 22011/330pm-430pm/WK_27_Lease_Leaseback.pdf

${ }^{4}$ Interview with Kim Scott, Blach Construction, March 25, 2014. 
system for selecting both the architect and the builder-developer is common. He recommends a "Best Value" system for the procurement of these important positions under L-LB. The most significant element of L-LB is that the District is relieved of the low-bid system required by legislation. With the low-bid mentality removed, it is possible for the builder, owner and designer to start working together on the design without the contentious nature of the bidding process. Bernards Construction reports the following:

This form of delivery (L-LB) alleviates the conflicts that often arise from the low bid procurement method, reduces the district's exposure to cost overruns and results in a shorter overall project delivery. ${ }^{5}$

Paula De Sousa, senior counsel with Best, Best and Kreiger, LLP reported in a 2004 conference for C.A.S.H. that L-LB, "Allows for the architect, contractor and District to be on the same team." 6 The criticisms of "low-bid" procedures are not just that the process is overly competitive; it is that the requirement to accept of the lowest bid is overly simplistic and prone to contention. ${ }^{7}$ The inherent constraints of limiting design information to the bidding period prevents a multidisciplinary consultation developed under Best Value procurement with design-assist services discussed below.

Leigh Coop, Director of Facilities of Vacaville USD pointed out that there is no other part of life, professional or personal, where the lowest price selection is required or even

${ }^{5}$ Bernards Construction website: http://www2.bernards.com/servicesexpertise/delivery-methods-services-contd/ Page 2.

${ }^{6}$ DeSousa, P. "Lease Leaseback Projects" C.A.S.H. Annual Conference, February 2004

7 Teicholz, op cit. p 7. 
logical. ${ }^{8}$ This precise point is the most significant finding of Dr. Teicholz and the Stanford Center for Integrated Facility Engineering as quoted in Chapter I.

The common source of contention in "low-bid" procedures is the completeness of the plans and subsequent conflict regarding claims of extra cost beyond the bid. No plans are perfect and some bidders make unreasonable assertions in order to cut their bid under that of the competition. The low-bid mentality promotes a temptation for the contractor to recover the money left on the low-bidder's table through Change Order Requests or Claims of Delay. If the construction industry fails to eliminate this antiquated process, and replace it with proven procurement procedures it will continue to be exposed to the criticisms of failed productivity and litigious nature.

\section{Best Value Procurement Compared to Low-Bid Requirements}

The Design-Build (D-B) practitioners have used Best Value procurement processes for years. Under Best Value procurement, contention is reduced, cost is adequately considered and skilled professionals are all given a well-developed opportunity to bring their best presentation to an impartial selection committee. It is a cooperative (while still competitive) procedure because the information delivered to the selection committee fundamentally changes the positions of the participants. It is important that the selection committee keep accurate records as to the scoring of the presentations and the calculation of the winning proposal. As discussed in Game Theory, the amount of information about the other participants in an interaction greatly increases the opportunity to reach

\footnotetext{
${ }^{8}$ Interview with Leigh Coop, Director of Facilities, Vacaville USD. 3/24/14
} 
equilibrium quickly. Thereby the best interest of each participant is maximized and the best interest of the group is maximized as well.

In one case recently, a Fresno-area district, using L-LB, put their the design out to bidding, and accepted alternative cost saving proposals to the design from 6 bidders. The normal process for low-bid projects is that no exceptions, (meaning no changes to the design) may be proposed on bid-day. This is an example of how districts are crafting their own project delivery designs. This approach includes much more information exchange in the bidding, making selection perhaps more complex, but also much more collaborative and effective. The bid was won by Diede Construction and reported by Brett Diede in an interview in May. The selection was made by comparing pricing, the completeness of the review and comments about constructability.

The oft-repeated, unsubstantiated claim that additional project costs arise by avoiding the competition of low-bid requirements is purely speculative. Studies show ${ }^{9}$ that there is no dependable comparison made to support the allegation that Best Value procurement costs any more for the same project built with a low-bid selection requirement. Every project is different; no comparison can account for all the variances in a multi-million dollar school construction project. The substantial advantage of avoiding the low-bid system is that the real cost of the project can be known to all parties much earlier by using designassist systems. It is significant that much more effort is placed in the design process using Best Value procurement and design-assist systems, however changes are

\footnotetext{
9 Vincent, J. "The Complex and Multi-Faceted Nature of School Construction Costs: Factors Affecting California" June 2008. Berkeley, Center for Cities and Schools, University of California. p 3.
} 
dramatically reduced, bid protests are eliminated and overall time is demonstrably reduced.

\section{Developing a High Functioning Team for Design Phase}

Now that the main participants have been selected in a fair, yet reasonably competitive way, a new opportunity presents itself to the owner. This point in the history of the project is the "preconstruction phase."

"Design-assist" or "design-build" services from the builder comprise the first major opportunity for collaboration on the project. This activity is contained in a services proposal delivered from the prospective builder to the district at the time of hiring the architect. The actual leases are signed when the design is approved.

The builder and the architect can be the same entity, but there is a tendency (under L-LB) to engage them separately to maintain the direct connection between the architect and the district. There is an opportunity to collaborate with the builder during the design, yet maintain the integrity of the client-architect arrangement through direct agreements. Specifically, in a separate developer-builder preconstruction services agreement, the builder becomes a consultant to review the drawings at specific intervals and among other services, develop construction cost analysis at the various stages of design. The design team, including the builder under a design-assist agreement, should be assembled no later than $25 \%$ of the design, according to Will Lichtig in $2006 .{ }^{10}$

${ }^{10}$ Lichtig, W. The Integrated Agreement for Lean Project Delivery, Article in Construction Lawyer Volume 26, No. 3, American Bar Association. 
John Nichols of HMC Architects ${ }^{11}$ has a prerequisite of demonstrated collaboration skills in their design-assist team members. He said:

In a collaborative design, like design-assist services, one gets smarter decisions from the designer, the contractor, even the owner. If the team together is committed to design it right the first time, design-assist can work well. HMC wants to know that there will be no hindrances between the designer and the owner. Given that relationship, having a good builder partner is helpful, especially in materials selections and cost analysis.

Design-assist is the point in the project where the Building Information Modeling (BIM) software produces its value. The design contains the actual specification for each element contained in it. The information about the product is electronically embedded in the drawing of the project so that the design-assist activity can be efficiently provided. The design can be accessed and adjusted by qualified participants to the design-assist process. When a change is made, a note is generated including who added what, when. Before BIM was created, the design could easily careen out of control of the designer. This fine-tuning can bring the builder, the sub consultants and even the subcontractors into the process as needed. This advance in design process makes the costs known early, reduces changes and reduces risk.

\section{Risk Reduction in “Open Book” and Cost Analysis Processes}

There is a companion exercise for the builder during the design-assist program, often used in recent L-LB and D-B programs: the development of a budget. In some cases the budget comes directly from the owner in the form of a maximum budget before the beginning of the project. Most of the time, the budget is established when the conceptual design stage begins.

${ }^{11}$ Nichols, J. HMC Architects, Irvine, Interview, March 15, 2014 
There are computer programs, such as dProfiler, that build a project cost estimate from the most basic information. Dr. Greg Starzyk of California Polytechnic State University (Cal Poly) Construction Management teaches the program currently. ${ }^{12}$ The program uses an electronic design tool that makes a "cost model" in a drawing tool similar to Google Sketch up and applying R.S. Mean's databases. It is highly valuable to know cost information early in the design process, because changes can be made in the design to conform to cost limits long before the design is completed. The cost model can be updated at any point, but three updates, at schematic design, design development and construction drawings appear to be common points in time for cost modeling and budget review.

A common discussion in the interviews (see Appendix E, Interviews) for this thesis is about the previously hidden costs of construction. These costs are now disclosed as a part of budgeting under new project delivery systems used by districts in L-LB projects. Mr. Wasserman of Capital Program Management stated that clients attained improved understanding of cost modeling when it included listing the builder's General Conditions, Overhead and Profit. Jim Forrester of Antioch USD calls this level of analysis in cost modeling an "open book" process. What is significant is that the school district can require that the builder-developer (a consultant during design-assist) to report all of the administrative costs and profit accruing to the builder. This process expands the cost analysis process to include actual percentages to be used by the contractor during construction. Mr. Forrester feels that the "open book" policy of Antioch USD is central

$12 \mathrm{Mr}$. Starzyk reports that a good conceptual estimate of standard office building can be assembled in a half-day or less. 
to the reduction of contention in L-LB because the district is informed as early as possible regarding all of costs in any part of the project. Further, "redundant contingencies" ${ }^{\prime 13}$ are avoided. These charges usually added by major subcontractors who are concerned about risk, are avoided because of the increased disclosure. When the design is approved by the Department of State Architect, (school construction is not administered by local jurisdictions) then the district and the builder can execute the lease for the site and the leaseback of the completed facility.

\section{Closeout Procedures under Lease-Leaseback}

Project closeout is similar in terms of substantial completion notice from the builder, punch list from the architect, and final payments. The close out requirements of the project can distribute profits or damages to parties in different ways, depending on the contractual level of integration of risk. First, the parties may look at the relationships in the project as partners sharing risk equally, now often called "Integrated Project Delivery." Profits over Guaranteed Maximum Price (GMP) can be shared, on a predetermined schedule, among parties. Losses can be shared up to specific portions or limits for each party. One technique is that the builder is guaranteed of being paid for his costs. Without including errors or defects, the contractor can be guaranteed of being paid back for all of his costs. The definitions of these costs as opposed to home office overhead or profit have been well defined in established time-and materials contracts. Please see Chapter VI ConsensusDocs 300 Paragraph 6.3 for further details on project close out procedures.

${ }^{13}$ Jackson, B. op cit, p215 


\section{A Brief Comparison of Project Delivery under L-LB to Design-Build Delivery Systems}

The Design-Build (D-B) system, the grandfather of all alternative delivery systems, is named after the design collaboration process. The comparison between the project delivery system under Lease-leaseback and D-B is informative.

In $\mathrm{D}-\mathrm{B}$, a design team consisting of a designer and a builder are given the go-ahead from the owner. As mentioned earlier, in the hybrid project delivery system under L-LB, designer and builder are commonly hired separately. Both are utilized as service providers through conceptual design, design development and construction drawings. The builder is engaged as a consultant about costs and materials At some point, (approximately at 75\% - 85\% design) the builder can produce a GMP. The Design Build Institute of America (DBIA) forged the way toward cooperative elements through Best Value procurement and the collaboration on design at the center of the D-B system. Under L-LB, the districts use the DBIA-style Best Value procurement system for the builder is usually divided into preconstruction consultation and construction.

\section{Guaranteed Maximum Price and Contingencies}

The end result of the cost modeling exercise under design-assist is the delivery of a GMP. Some contracts (ConsensusDocs 300) use Project Target Cost Estimate (PTCE). There are also different methods of utilization of contingencies, savings, distributions of cost overruns that can be changed or adjusted to reach equilibrium of cost versus risk for each party and for the project. 
The GMP will contain all the itemized costs of the project; the general conditions costs and profit plus defined contingencies. Under the GMP process, payment is made for actual costs, plus general conditions, plus profit for the period. Mr. Forrester of Antioch USD and Mr. Wasserman of CPM, use competitive bidding for the subcontractors, combined with an "open-book" system for the builder as back up for the GMP.

Any increase in project scope is taken from the district's portion of the contingency. The contingency use depends on the change. The size of the change and how it arose are the topics in the GMP close out process and contingency use agreements. One can see how the cooperative process in negotiation can be useful in the project operations. Cooperative techniques often include sharing of a contingency balance, which can be substantial, at the end of the project. Further, the cooperative nature of cost modeling, leading directly to a contract price, greatly expands the owner's knowledge of costs. In open-book policies, this knowledge encompasses all the mark-ups and profit to the builder. Sharing information greatly increases the chances of finding equilibrium for any cost issues because of the positive effects of expanded communication in a cooperation game as we have learned from Game Theory.

\section{Green Building and Commissioning}

These processes require new relationships between parties. The parties are tied together by building performance requirements extending a year or more after the substantial completion of the building. This is an area for further research as these significant process develop a history of integration into the industry. There is a ConsensusDocs addendum (CD 310) that can be used to capture these new tools. 


\section{Dispute Resolution}

Modernization and new constructions of school facilities pose different levels of risks but no project is risk-free. One of the major sources of risk is the transactional cost of resolving a contended issue. There are cooperative methods of dispute resolution and methods of scaling them to fit the size and apparent risk picture for any project.

The new standard dispute resolution process begins when the parties to the project cannot settle an issue on site. It goes to mediation but if no agreement is reached, it goes to an arbitration of court action. Starting ten years ago, a new first step has developed called mitigation. Mitigation consists of requesting a hearing before a Dispute Review Board (DRB.) DRBs are the cooperative solution to dispute resolution. They are cooperative because preplanning and reduced cost of hearings lowers the transactional cost of obtaining an independent review. The report of the DRB is not binding, but it is “discoverable.” As Kurt Dettman, a DRB trainer, pointed out, the reports are extremely influential in subsequent proceedings. ${ }^{14}$ The independent review is a good example of increased information about the interaction that generates a faster path to equilibrium. There are just three steps to operating a DRB:

1. Select the DRB at the outset of the project. The board consists of one representative each from the designer, the builder and the owner. These senior professionals read the weekly meeting minutes and all change or issue related correspondence.

2. Convene a hearing, if needed, with the project professionals presenting their material. The board produces an opinion that is non-binding and discoverable in court if necessary.

3. The parties meet to conclude the issue with a change order or other arrangement suggested by the independent opinion of the matter.

14 Dettman, K. Dispute Review Board Training Session, May 2013, Georgia Tech, Atlanta GA. 
The Dispute Review Board Foundation was formed in the early 1970s with the purpose of recording the results of projects with DRBs. Their records indicate that, of the 2200 DRBs convened from 1995 to 2010 in North America, less than 2\% went on to an additional arbitration or litigation. ${ }^{15}$ The costs of operating a DRB ranges from $0.05 \%$ to $0.25 \%$ of construction cost, depending on the number of issues presented to the board. It is recommended that the parties share the costs of DRB equally. ${ }^{16}$ ConsensusDocs 300 , a current form contract, includes DRBs in their Article 23, Dispute Resolution.

\section{The Exception that Proves the Rule}

As a result of literature review regarding Game Theory, that greater information sharing is the main mechanism for cooperative construction. Starting with BIM, and including all the techniques, through DRBs, it is increased information transfer that makes the best project with the least contention. San Francisco Unified School District (SFUSD) provides an excellent example of the effect of expanded communications upon a change in productivity. In an interview with Wazi Choudhry, Director of Project Management for the district, he described a very successful modernization program for San Francisco Schools. In a program comprised of 115 school modernizations, all were competitively bid. The result was $100 \%$ on-time delivery and only 2 resultant cost claims. And all projects were competitively bid with low-bid selection. Upon further inquiry, SFUSD's process contains a clear reason for this extraordinary success.

15 Dispute Review Board Foundation, Practices and Procedures, Jan 2007 DRBF, SelfPublished. Section 1, Chapter 4, Costs. Print.

16 Dispute Review Board Foundation, “Practices and Procedures”, Jan 2007. 
SFUSD spends an entire calendar year studying, testing, analyzing and digitizing every project before bidding. The District creates priorities, sequences activities, creates milestones, and describes in detail every aspect of the project in advance. Mr. Chowdhry described the information produced on each building as filling a full-size binder three and one half inches thick and containing every possible description, test, and photography of existing condition. This accompanies a set of electronic drawings of the required finished conditions. The District includes a master schedule of how the modernization will be phased.

This substantial flood of information changes the bidding process into a cooperative one. The SFUSD modernization program was extremely cooperative, given the amount of information about existing conditions and the detailed planning of the project to be bid. In most cases, a bidder has a set of plans and site visit "walk-through" to learn the existing conditions. This usual level of information exchange is commonly inadequate in creating a comprehensive understanding of a modernization project hence contracts must include considerable contingencies for risks.

There are visible risks, observed in a walk thorough, such as blocked access, difficult workspace or inadequacy of utilities or lay-down yard. "Reasonably Unforeseen" risks include quality of plumbing, wiring, structure and deterioration. These two different risks carry different payment responsibilities, so they often become contentious. Unforeseen risks are substantially reduced by detailed Assessment Phase Reports such as provided by SFUSD. 
The SFUSD has resources far greater than most of the school districts in the state. They hired consultants for the detailed analysis of existing conditions and skillfully assembled the information necessary to define the project in a way that produced very accurate bids. The challenge for most school districts will be to invest the correct amount of planning into modernization projects, regardless of the project delivery system. The potential cost of settling claims over reasonably unforeseen conditions is arguably less than the cost of the development of the detailed studies. 


\section{CHAPTER V}

\section{Right Attitude}

Cooperative Construction is a combination of processes and approach. The processes are listed in previous chapters along with a description about how and why to apply them. In addition, the right process needs the right approach. Two construction processes embody the right approach toward cooperative construction and both have been in place for many years. They are Lean Construction and Partnering. Both of these systems contain the right attitude (especially for the increased flow of information needed) to create a cooperative construction project. According to the research, when the right processes, the right attitudes, and the right contracts are in place, the benefits of cooperation will be attainable. These are the two of the systems to develop the right attitudes.

\section{Lean Construction}

Lean Design and Construction is a production management-based approach to project delivery. ${ }^{1}$ Developed in 1997 by Glenn Ballard and Greg Howell, Lean brings the right attitude to the construction industry. Glen Ballard, in an interview from 2012 discusses bringing the value to the customer with ever-decreasing waste. Mr. Ballard reports that the philosophy of Lean Construction is dedicated to developing the people in the organization to their best selves. Also citing "continuous improvement" in workflow and project design, Lean Construction is the envelope containing the right attitude necessary

\footnotetext{
${ }^{1}$ http://www.leanconstruction.org/about-us/what-is-lean-construction/ This is a summary review by Glenn Ballard of Lean Construction. Mr. Ballard is the Cofounder and Research Director of Lean Construction Institute. The 4 minute video is a good introduction to Lean, particularly the right attitude toward construction, developed by the practice.
} 
for change in the construction industry. Co-incidentally, Mr. Ballard reports $15 \%$ to $20 \%$ well-documented savings compared to traditional construction.

It is not enough to have tools, some methods, software and all that stuff, that's allimportant and critical, but it's not sufficient. The fundamental change that is needed is a change in behavior. The change in behavior is in the way we supervise people... especially the way we behave when something goes wrong. Is it seen as an opportunity to learn or is that seen as a search for a victim? ${ }^{2}$

The "Last Planner System" (LPS) was developed by Howell and Ballard. It is a set of processes that recognizes importance of individual workers and their foremen on the project. The central concept is that the best planning is done at the lowest level of hierarchy. Under LPS, it is recognized that the craftsmen and their foremen know best what they can perform, and in what time frame. The management of a project is then focused on this knowledge, and a culture of accuracy is built around it. The worker is further empowered to stop production when any defect is found. ${ }^{3}$ Tight sequential scheduling, avoidance of overproduction and eliminating waste of resources are the foundations of Lean Construction and the basis of a culture with the best chance of improving the construction industry today. Both of the issues referenced by the Construction Users Roundtable report of 2008, inefficiency and contentiousness, are well addressed by Lean Construction.

Lean Construction thrives on cooperative techniques, the culture built around the respect for the worker in the "Last Planner System," and a basic project-wide effort at continuous improvement. Lean Construction is a culture. Recognition of the success of Lean

\footnotetext{
${ }^{2}$ Glenn Ballard, Lean Construction introductory video, op cit, at 4:00 minutes. 3 This "no defect" aspect of the culture surrounding Lean Construction originated with the development of the Toyota Way. Taiichi Ohno developed the principles that became the backbone of Lean Construction.
} 
Construction has spread broadly throughout the major construction companies interviewed for this paper. The relationship between Lean Construction and the recognition of cooperation as an organizing principle for the construction industry is significant. Every process in Lean has cooperative aspects. When we define cooperation as rational parties constantly seeking the best result for the project, we see the close alignment with Lean Construction.

\section{Partnering}

Major founding documents about Partnering were published by The Army Corps of Engineers in $1991^{4}$ and the Construction Industry Institute (CII) at Texas A\&M University in 1993. ${ }^{5}$ The International Partnering Institute published a Special Report in June 2008 showing the results from over 20 years of Partnering. ${ }^{6}$ The Special Report reported significant cost savings of $10 \%$ and time savings of $20 \%$ based on research from CII, based on Partnering programs.

With such a long history, Partnering presents its own record as a validation of cooperative construction techniques. The standard partnering program consists of a weekend workshop, held off-site, after the bid award and before the Notice to Proceed. Participants include the owner, designer, builder and the major subcontractors. Independent consulting firms conduct the workshop. Follow-up sessions are used occasionally. The goal of the workshop is to allow the parties to meet in advance of the

\footnotetext{
4 US Army Corps of Engineers, "Pamphlet \#4, Partnering: A Tool for USACE. Engineering, Construction and Operations,” Dec 1991. Rev. May 2010. 5 Construction Industry Institute, “The Partnering Process," RR102-11. 1993, Web. https://www.construction-institute.org ${ }^{6}$ International Partnering Institute, "Collaborative Construction, Lessons Learned for Creating a Culture of Partnership." IPI, (2008) p 14
} 
pressure that starts as soon as the Notice to Proceed is issued. The workshops are intended to increase communication between parties, as well as specific goals, introducing Total Quality Management (TQM) techniques, Alternative Dispute Resolution (ADR) and, team-building exercises.

Partnering can be adjusted to fit different situations. In October 2006, the San Diego City Schools and the Division of the State Architect produced a summary report outlining the progress made in a Strategic Partnering Program operated by Orgmentrics, of Livermore, CA. This was a larger scale program than a standard partnering program. It was a planning session for personnel from the entire School District and the State Architect to coordinate activities surrounding $\$ 1.5$ Billion of construction needed in San Diego starting from Feb 2002. Significantly, the program introduced of Design-Build to San Diego. The Strategic Partnering program introduced the roles to the school facilities professionals in the region. This program is important because its goal was to produce a cooperative relationship between the District staff and the Office of the State Architect. The point is that partnering sessions can have the right attitude for cooperation and can be adjusted to fit nearly any construction scenario.

Nowhere does Partnering have a longer history than the California Department of Transportation (CalTrans.) The partnering program at CalTrans has its own bi-monthly newsletter, awards program and even a logo, stating, "Partnering, Our Way of Doing Business." For example, the 2012 awards program, covering 24 projects across the state, showed about a half of one percent savings, attributable to Partnering. ${ }^{7}$ This savings

\footnotetext{
7 “2012 Award-Winning Results” June 2102, California Department of Transportation, Web. http://www.dot.ca.gov/hq/construc/partnering.html
} 
amounted to $\$ 56$ million, quite a handsome sum although a small sliver of CalTrans' budget for the year. Also impressive was a savings of $10 \%$ of the construction period duration of the 24 projects in the awards program.

The cooperative nature of Partnering, particularly its personal aspects, is well represented in a journal article in 2011. That year, Aaron Anvuur and Mohan Kumaraswamy published "Measurement and Antecedents of Cooperation in Construction" in the Journal of Construction Engineering and Management. ${ }^{8}$ The study followed 140 professionals in construction in projects in Hong Kong. Rules compliance, altruism, and helping others with work-related problems were surveyed as well as job satisfaction and perceived legitimacy of rules. Incentives and sanctions were not effective in promoting cooperative behavior. As it turned out, it was improved job satisfaction and increased perception of legitimacy of rules that were effective in improving cooperation. The variables of job satisfaction and perception of legitimacy are both positively effected by Partnering.

\section{Partnering and Lean are Non-Contractual}

Neither Lean Construction nor Partnering produce contractual requirements. Attendance at partnering programs is required in CalTrans contracts, but no changes to the contract result from the process. The popular ConsensusDocs 300 form contract (see Chapter VI) only mentions Lean Construction once in paragraph 3.2 and even then it is only a reference, not a requirement. Partnering is not mentioned at all in ConsensusDocs 300, however, Article 3, paragraphs 3.1 through 3.4 , "Collaborative Principles," lists

${ }^{8}$ Anvuur, A and Kumaraswamy, M. "Measrurement and Antecedents of Cooperation in Construction," Journal of Construction Engineering and Management, 138 (2011) 797-810. Print. 
cooperative and collaborative behavior in elaborate detail. See the following Chapter "Contracts and Risks."

In an interview with Neal Flesner of Ventura Consulting, a partnering facilitator, I asked if he felt that Partnering was diminished by not being a contractual obligation. He said that he highly valued that the cooperative behavioral lessons of Partnering was not contractual requirements He feels it's crucial that Partnering (and all cooperative behavior) be driven by, rather than merely required of, the professionals in the construction industry. The success of cooperative construction techniques is connected to the right attitude as well as the right contractual language.

The way cooperation stands now, it can be required in modern contracts and also the right attitude developed experientially in Partnering or the fostered in the culture of Lean Construction techniques. The right contracts work together with the right attitudes. 


\section{CHAPTER VI}

\section{Contracts And Risks}

The right contract is the bridge to cooperative construction. What is in a form contract that makes it useful for cooperative construction?

There are two excellent organizations producing form contracts today, The American Institute of Architects (AIA) and ConsensusDocs. The main contract elements that are integrated are:

1. Design-Assist The skills of the builders of the project are integrated into the design phase.

2. Design Liability Because of many parties contributing to the design phase, the design liability is divided into proportional shares.

3. Contingencies Since the delivery of a GMP or a Target Value can occur prior to the completion of the drawings, appropriate contingencies must be added to the project budget. There are contingencies for the owner, designer and builder.

4. Incentive Compensation The builder's project profit and a portion of the owner's contingency can be distributed to the builder if arranged. For example early completion or savings of owner's contingency can have incentives associated. In some "single entity" projects, all savings in contingencies are distributed to all parties under prearranged rules.

5. Cost Risk Using Guaranteed Maximum Price, the builder is exposed to excess costs. Under Target Value, the cost in excess of contingencies might be split between parties on an agreed proportion.

This is a review of ConsensusDocs 300 . The AIA family of cooperative agreements, while differently arranged, are also worthwhile tools in the development of cooperative construction. Comparison of the differing contracts is beyond the scope of this thesis.

\section{ConsensusDocs 300}

The ConsensusDocs $300^{1}$ (CD300) has specific paragraphs that create the mechanism to operate the cooperative project. This is a multi-party agreement. For purposes of an

\footnotetext{
${ }^{1}$ Quoted portions of the agreement are attached in Appendix $\mathrm{G}$ and cited by article and paragraph number.
} 
analysis of the cooperative elements in CD300, it is not necessary for the contract to be a three-party agreement. The cooperative elements could be placed in two separate agreements to fit the L-LB system sequence and still be a productive contract in terms of providing the benefits of cooperation. The builder is called the constructor in CD300. Let us review the many cooperative elements of this contract just as it applies to the design phase:

- Article 3, Collaborative Principles Paragraphs 3.1 through 3.4 list behaviors, activities and forms the Collaborative Project Delivery Team (CPD.) This is an operational team and is overseen by the Management Group.

- Paragraph 3.6, Designer Responsibilities “...the designer shall draw upon the assistance of the Constructor...” But retains “...overall responsibility for all design decisions as required by applicable state laws."

- Paragraph 3.7. Constructor's Responsibilities “...the constructor shall assist in the development of the project design but shall not provide professional services which constitute the practice of architecture or engineering unless the Constructor needs to provide such services in order to carry out its responsibilities for construction means, methods, techniques sequences and procedures..."

- Paragraph 3.8, Collaborative Risk Allocation This section gives the parties the choice to avoid suing each other or limit liability. The next paragraph 3.8.3 waives all consequential damages among the owner, designer and builder.

- Paragraph 3.9, Reliable Commitments This paragraph adds emphasis to the normal process of making representations in, for example, a weekly meeting. The 
paragraph has no penalty provision, but is an affirmative statement of positive intentions and adds influence to the verbal representations.

- Paragraph 3.10, Quality Plan This paragraph assigns specific duties to the parties and includes language like "continuous improvement" from Lean Construction techniques. The article requires coordination among the parties.

- Article 4.1, Management by the Management Group Names the group members, one each from Owner, Designer and Builder. Article 4.6 Decision Making tasks the Management Group to find consensus where ever possible Further, paragraph 4.6 reports that "the Management Group shall act in the best interests of the Project as a whole without consideration to each member's own interest..." Each of the participants in the Management Group will need considerable leadership skills to find a consensus agreement that falls inside the parameters of Article 4.6. Failing consensus, the Owner shall operate under Article 23, Dispute Resolution.

- Article 4.9, Principles of Communications "The Parties acknowledge that a truly collaborative relationship requires consistently open, honest and clear verbal and written communications..." While this language might be considered by some to be overly expressive, the subsequent paragraphs provide good quality parameters for communications, especially given the velocity and size of the flow of data on and off the desks of these professionals.

- Paragraph 5.2.4, Management Group "The Management Group shall jointly manage the budget..." The budget is not refined at the beginning of the project. It is the Management Group, not the builder that manages the budget. 
- Paragraph 5.3, Access to Preconstruction Information The CPD team shall review the design "for errors or incomplete information that would prompt the Constructor to include additional contingency... “ "The CPD team shall also suggest options for additional preconstruction investigation of existing conditions for Management Group consideration, including the cost and potential benefit of differing levels of potential preconstruction investigation." This section would be particularly beneficial in modernization of an older school. The builder or a subcontractor can ask the CPD to test materials in existing conditions. This would avoid a project interruption in the event that some materials might require special demolition procedures.

- Article 6, Development of Design and Collaborative Preconstruction Services Paragraph 6.1 "Collaborative Design Principles In order to achieve the Project objectives, the design must occur in a collaborative manner, informed by a freeflow of accurate information concerning the process, quality, cost and schedule. While retaining overall responsibility for the Project design, the Designer must work collaboratively with the other members of the CPD team, drawing on their respective expertise in order to achieve the project objectives." This is a high standard of duty for the Designer. It seems that a facilitated meeting, such as a partnering session, would be commonly needed to get this process under way. The leadership skills of the CPD team members would likely be tested if they were new to this process.

- Paragraph 6.2, Scope "A description of the scope of services to be provided by Designer and Designer's consultants and the documents to be developed during 
each phase of progression of the design is set forth in Exhibit C. The Management group shall oversee development of the design documents for the Project and develop milestone schedules for the preconstruction phase.“

This is a much tougher standard for scheduling design production, but it might be a useful tool for managing this difficult phase.

- Paragraph 6.5, Pull Based Design “The designer shall use 'pull based' planning principles to develop the Design Documents. Pull based design advanced the design only so far as has been anticipated and approved for any given time period by the Management Group, with the designer only performing services that are shown on the applicable Project plan..." The designer is responsible for any costs or rework caused by proceeding beyond what the Management Group has approved. This makes the designer's job more challenging because incremental design is more time consuming than just a go-ahead. However, the benefit for the project is that each step is well-reviewed and presumably more complete.

- Paragraph 6.6, Notifications "Consistent with the collaborative approach set forth in this Agreement, should the constructor, Trade Contractors or Subcontractors in the course of performance of obligations discover any errors, omissions or inconsistencies in the design documents... they shall promptly notify the Management Group..." This is a powerful mandate because it authorizes all the parties to continuously review the design. This is like having a constructability review underway all the time. Considering Paragraph 6.9 states, "The parties may establish a BIM approach to design and construction of the Project, providing continuous and immediate availability of reliable integrated and coordinated 
design, scope schedule and cost information. " There is an addendum for BIM use that has 9 pages of details for responsibility and ownership of the design. This document, ConsensusDocs 301, is informative but the cooperative language is in the CD300.

- Paragraph 6.13, Target Value Design "The Constructor shall provide Target Value Design support during the development of tie Project design and more fully discussed in Article 8. " Following up is Paragraph 6.14, Value Identification and Creation, creating an ongoing value engineering program for the design period. Paragraph 6.15 calls for an ongoing constructability review of the design. These services add significantly to the accuracy of any design.

- Article 7, Project Planning and Schedule Paragraph 7.2.1, Pull Planning. This paragraph is the heart of the approach imported from the Toyota Way. This article sets up "just in time" delivery and the required ties between subcontractors necessary for Pull Planning. This paragraph is perhaps the most precise implementation of a cooperative technique. It requires all parties to informs the other parties of completion of an activity thereby signalling the need (the Pull) for performance of the next activity.

- Article 8, Construction Budget and Cost Modeling Paragraph 8.3 requires the development of the Cost Model and Project Target Cost Estimate, discussed in Chapter IV, Tools. Paragraph 8.3 also contains requirements and definitions of project contingencies. 
- Article 10, Constructor's Compensation Article 11, Incentives and Risk Sharing Articles $11.4, .5$ and .6 provide fill-in blanks to insert the amount of risk to be borne by each party.

- Article 23, Dispute Resolution Paragraph 23.2 Requires direct discussions leading up to a referral to the Management Group, often referred to as "step negotiations." Specific timetables are required of each step.

- Paragraph 23.3 Mitigation This paragraph gives the parties a choice whether to appoint a Project Neutral or a Dispute Review Board prior to a binding dispute resolution process.

These provisions appear in Appendix G. 


\section{CHAPTER VII}

\section{Conclusion}

In California public schools, there are 1000 owner entities. It will be challenging for this diverse owner group to achieve cooperative construction on a large scale. Years of effort will be needed to have most (or even many) school districts adopt cooperative processes. It is the job of the construction industry itself to become cooperative for its own benefit and the benefit of the schools.

Dr. Teicholtz's graph (see page 4) shows that the weak labor productivity in construction from 1964 until present is stunning in size. Some of the weak productivity in the construction industry won't ever be removed, but the goal is to eliminate waste as soon as possible, as emphasized by Lean Construction.

In Game Theory, Robert Axelrod found the motivation for cooperation in 1984. He called this: "Enlarge the Shadow of the Future." Cooperation "can be stable if the future is sufficiently important relative to the present."

Players were more cooperative and successful when they had a reputation of reciprocity and reasonably expect to play again. They also were more cooperative when it was suggested that cooperative choices might work well for them in the long run. The construction industry must keep its eye on the horizon; the future needs to be as important as the present. The future will contain a construction industry where interests of the individual are considered simultaneously with interests of the project.

\footnotetext{
${ }^{1}$ Axelrod, R. op cit. p 12
} 


\section{BIBLIOGRAPHY}

Alberti, Leon Battista. \& Sinisgalli, Rocco , 2011, On Painting: A New Translation and Critical Edition, Cambridge University Press, New York, ISBN 978-1-107-000629. Print.

Anvuur, A and Kumaraswamy, M. "Measurement and Antecedents of Cooperation in Construction," Journal of Construction Engineering and Management, 138 (2011) 797-810. Print.

Army Corps of Engineers, Pamphlet \#4, Partnering: A Tool for USACE. Engineering, Construction and Operations, Dec 1991. Rev. May 2010. Print.

Axelrod, R. The Evolution of Cooperation, Robert Axelrod, Basic Books, New York, 1984 Print

Ballard, Glen, Lean Construction saves money and improves productivity. YouTube. Posted May 28, 2011, Accessed, April 15, 2014 Web http://www.youtube.com/watch?v=dJyCpuR9xck

Bayer, Richard. "Leader Profile, Dick Bayer," The Military Engineer. July 2013, Vol. 105, Number 684, Print

Beard, J. Loulakis, M. Wundram, E. Design-Build: Planning Through Development McGraw-Hill, New York, 2011, p.14 Print

Bernards Construction, Services, Delivery Methods, Lease-Leaseback Accessed March 25, 2014, http://www2.bernards.com/services-expertise/delivery-methods-servicescontd/ Web.

Bongiorni, Michael, Why is the US Construction Industry Slow to Embrace New Partnering Agreements for Project Delivery. IDBE Essay One, University of Cambridge, 2011. Print.

Brunner, Edward. Financing School Facilities in California, Essay, Quinnipiac University 2011 Camden, Ct. p54 Print.

California Air Resources Board Environmental Health Conditions in California's Portable Classrooms. Department of Health Services, 2011, Print. http://www.arb.ca.gov/research/apr/reports/13006.pdf

California Department of Education State General Obligation Bond History CalEdFacts,Web. http://www.cde.ca.gov/ls/fa/sf/cefgobondhistory.asp 
California Department of Education Fingertip Facts, 2011, Web.

http://www.cde.ca.gov/ds/sd/cb/ceffingertipfacts.asp

California Department of Transportation, “2012 Award-Winning Results” June 2102, (CalTrans), Web. http://www.dot.ca.gov/hq/construc/partnering.html

Center for Cities and Schools, University of California, School Facilities in California, 2012, Executive Summary p. ii, Web http://citiesandschools.berkeley.edu/reports/CCS2012CAK12facilities.pdf

Chialtas, Andreas. Court Validates Use of Lease-Leaseback Construction Contracts for School Districts Atkinson, Andelson, Loya, Ruud \& Romo, News Release, June 25, 2013. Cerritos, CA.

Web.http://www.aalrr.com/news and events/search/Andreas\%20C.\%20Chialtas/n/ $\underline{\mathrm{n}}$ Print.

Coalition for Adequate School Housing, Hearing Summary: California's K-12 Educational Infrastructure Investments. C.A.S.H. Register August 2012. Print.

Seminar Schedule Coalition for Adequate School Housing, 2011. Web. http://www.cashnet.org/meetings/2011_Annual_Conference/TuesdayFebruary2220 11/330pm-430pm/WK_27_Lease_Leaseback.pdf

ConsensusDocs Contract 300 Catalogue of Contracts Print. https://www.consensusdocs.org/catalog/collaborative

Construction Industry Institute, The Partnering Process, RR102-11. 1993, Web. https://www.construction-institute.org/scriptcontent/more/rr102_11_more.cfm

Coop, Leigh. Vacaville Unified School District, Interview with the Author, Vacaville, CA March 24, 2014

Construction Users Roundtable, A/E Productivity Committee, Strategy: CollaborationIntegrated Information and Project Life Cycle in Building Design, CURT, 2004, Web. http://www.curt.org/Training-WP1202-Collaboration-IntegratedInformation-and-the-Project-Life-Cycle-in-Building-Design.aspx

Department of General Services, State Allocation Board. Unfunded Approvals, Lack of AB 55 Loans; as of April 7, 2014 Modernization Projects, Web. http://www.documents.dgs.ca.gov/OPSC/Resources/Unf_Lst.pdf

DeSousa, Paula. Lease-Leaseback 2005- A Whole New Ballgame? C.A.S.H. Annual Conference, Presentation, March 2, 2005 Web. https://www.cashnet.org/resourcecenter/resourcefiles/300.pdf 
Dettman, Kurt. Dispute Review Board Training Session, May 2013, Georgia Tech, Atlanta GA. Personal Contact.

Dispute Review Board Foundation, Practices and Procedures, Self published, 2007 , Section 1, Chapter 4, Costs. Print.

Eastin, Delaine, California Secretary of Education, C.A.S.H. Annual Conference 1996, Red Lion Inn, Sacramento, CA. Presentation attended by Author.

Fallon, Michael. Considerate Constructors Scheme An Overview 1997. Considerate Constructors. Web. http://www.ccscheme.org.uk/ and personal observation, July 2002.

Federal Highway Administration, , Design-Build Effectiveness Study, Jan 2006, p 10. Print.

Fourie, Ferdi Mr. Fourie is also a visiting Professor at Virginia Tech. Mr. Fourie was quoted from the 2013 Construction Superconference, December 2013, Palace Hotel, San Francisco, CA. Interview with Author.

HMC Architects Aging Portable Classrooms: Santa Ana's Replacement Plan to Save Dollars, Web. Accessed, April 23, 2014. Web.

http://blog.hmcarchitects.com/aging-portable-classrooms-santa-anas-replacementplan-to-save-dollars/

Howell, Gene. Lean Construction Opportunities, Ideas, Practices. Speech at Lean Construction Institute Workshop, Seattle, WA, Sept 2008. Web.

International Partnering Institute "Collaborative Construction, Lessons Learned for Creating a Culture of Partnership.” IPI, (2008) p 14

Jackson, Barbara. Design-Build Essentials, 2011, Delmar Cengage Learning, Clifton Park, New York p. 4 Print.

------------- Construction Management 433, Integrated Project Delivery, CalPoly Spring 2013. Author attended class.

Kotter, John. "Leading Change" 1996 Article Harvard Business School Press, p5 Print.

Lawrence Berkeley Laboratory Toward cooler, quieter, energy-efficient portable classrooms Lawrence Berkeley Lab, Science Beat Newsletter, August 2002. Print.

Lean Construction Institute Target-Value Design: Nine Foundational Practices for Delivering Surprising Client Value Lean Project Consulting, Inc. 2007 Web. www.leanproject.com

Lichtig, Will. Hypothesis Handwritten message. Nov 2013. 
Nichols, John. HMC Architects. Irvine , CA Interview with the Author, May 10, 2014

Nowak, Martin. “Evolution of Cooperation," Scientific American, July 2012, 35-39 Print.

Polak, Ben Economics 159 Game Theory Open Yale Courses, Yale University, 2008, Web. Http://oyc.yale.edu/economics/econ159/lecture Ten classes are available online, one hour each, the author reviewed all.

Savidge, William, Office of Public School Construction, Sacramento, CA Interview with the Author. , Oct. 2013, Jan 2014

Scott, Kim Blach Construction, Fresno, CA Interview with the Author, March 25, 2014

Starzyk, Gregory. Construction Management 415, Integrated Project Delivery Studio CalPoly, Fall 2013, San Luis Obispo, CA. Author attended class.

Teicholz, Paul. "Labor-Productivity declines in the Construction Industry: Causes and Remedies (Another Look)" AECbytes Viewpoint \#67, Mar 2013. Print.

Vincent, Jeffrey. California's K-12 Educational Infrastructure Investments: Leveraging the State's Role for Quality School Facilities in Sustainable Communities. 2012, Berkeley: Center for Cities and Schools, University of California. Print.

Wasserman, Michael. Capital Program Management, Sacramento, CA Interview with the Author, Jan 15, 2014 


\section{APPENDIX A}

Timeline of School Milestones in Funding and Regulation

11879 CA constitution amended to allow local bonds.

21927 Uniform Building Code created

31933 Field Act after Long Beach earthquake

41947 State Allocation Board created (SAB)

51949 First statewide bond for school facilities

$6 \quad 1950 \quad$ Student enrollment doubled by 1960

$7 \quad 1957$ Lease Leaseback legislation passed.

$81970 \quad$ Student enrollment declined until 1982

91976 Leroy Greene Lease-Purchase Program

101976 Rejection of \$200 Million bond issue

111978 Proposition 13 passed, limiting local funds

121979 SAB forgave old loan program balances.

131982 Steady student enrollment increase

141986 SAB had $\$ 2.3$ billion backlog

151986 State initiative allowing local bonds with $2 / 3$ vote

$161986 \quad 7$ small statewide bond issues pass through 1992

171992 "No Room for Johnny" Little Hoover Commission Report

181994 Rejection of statewide bond issue, \$200 million.

191998 Leroy Greene School Facilities Act

201998 First of 4 major statewide bond issues through 2006 passed.

212000 Passage of 55\% approval of local bond issues.

222001 California invests more than US avg. through 2004

232012 SAB has $\$ 100$ million backlog in modernization

242013 All funding exhausted.

$252013 \quad 87,000$ enrollment increase in next decade in 36 counties 


\section{APPENDIX B}

\section{Cooperative Processes}

The leading cooperative processes are:

1. Building Information Modeling. (BIM) It is an expansion of computer-aided design where the actual drawings include the specifications of the products shown.

2. Design-Build (D-B) project delivery systems. The designer and builder are on the same team proposing to deliver the completed project to the owner. In school construction, the lease leaseback program has been the financial structure most used for Design-Build projects recently.

3. Integrated Project Delivery (IPD) project delivery systems. The owner, designer and builder team up further in sharing risk and rewards.

4. Lease-leaseback development systems in CA Schools. Lease arrangements that allow any project delivery system to be utilized in school facilities construction in California.

5. Best Value procurement systems. Receive proposals combining cost and qualifications from parties instead of competitive bidding where the acceptance of the low bid is required. Owners rank proposals by desirable qualities, experience, individuals and presentation. Although this is a competitive system, it has the cooperative element of increased information at the time of agreement. In Game Theory, increased knowledge in a game accelerates the discovery of Nash's Equilibrium. This process is actually a 
cooperative process due to the better-informed Owner participant at the point of agreement.

6. Prequalification of Bidders. While not cooperative, per se, a new prequalification process greatly expands the information about a bidder by requiring financial, legal and professional reporting from them in advance of bidding. This became part of the required processes under the Education Code as of the beginning of 2014. Most districts have developed new prequalification programs with carefully managed forms, presentations and renewal cycles. This is an substantial improvement upon low-bid requirements.

7. Lean Construction. The elimination of waste in construction. Sometimes estimated at $40 \%$ of the cost of construction, waste of both materials and time are reduced everywhere it can be found. A culture based on recognition of workers knowledge called "Last Planner System" engages that knowledge in managing the project. Broadly accepted. Lean Construction is growing quickly.

8. Teaming Agreements are contractual obligations between partners in D-B and other cooperative professional relationships.

9. Partnering. Partnering is a non-contractual form of team building. While not proven to statistically produce project savings, many participants expressed operational improvements. The California Department of Transportation (CalTrans) Has performed Partnering sessions on hundreds of projects for over 10 years. 
10. Cost Modeling. New techniques in cost analysis bring out cost information at very early stages and track cost as the design is developed. Large efficiencies in design and eventual construction can be built on cost modeling software coordination with BIM software in the near future.

11. Constructability. The builder is included in the design process and constructability is reviewed as the project is being designed, not after it is completed. The scope of the constructability review can be expanded to include review of process and ease of assembly.

12. Value Engineering. (VE) This means producing the same scope at a lower cost. It does not mean producing less product or lesser quality product.

13. Green Building. The large consumption of resources and $40 \%$ waste will be one of the largest drivers to force the construction industry to improve.

Commissioning causes design and building to work together.

14. Information and Communication Technology. (ICT) Starting with BIM, ICT is transforming the construction process rapidly currently. Mobile applications, widespread instantaneous communications as well as co-location strategies for increased communications are expanding rapidly.

15. New Contracts. AIA and ConscensusDocs. 300 New Contract forms allow owners to guide a project into cooperative methods.

16. Project-wide Insurance and Risk Management. Often called OwnerControlled Insurance Programs, (OCIP) all parties are required to sign up for a project wide risk management system. It is a process of financing risk across 
many clients on the project and reducing the premiums for all because of the multiple investors.

17. Dispute Resolution. Dispute Resolution Boards (DRB) and on-site dispute review processes are transforming risk of the transactional costs of dispute resolution. In DRB's, the parties agree to have disputes reviewed by an independent panel of experts who have been staying abreast of the project from the outset. On-site dispute resolution structures, included in contractual agreements are available in IPD delivery systems. 


\section{APPENDIX C}

\section{Education Code 17406.}

The attached section of the California Education Code is the authorization for LeaseLeaseback projects.

17406. (a) Notwithstanding Section 17417, the governing board of a school district, without advertising for bids, may let, for a minimum rental of one dollar (\$1) a year, to any person, firm, or corporation any real property that belongs to the district if the instrument by which such property is let requires the lessee therein to construct on the demised premises, or provide for the construction thereon of, a building or buildings for the use of the school district during the term thereof, and provides that title to that building shall vest in the school district at the expiration of that term. The instrument may provide for the means or methods by which that title shall vest in the school district prior to the expiration of that term, and shall contain such other terms and conditions as the governing board may deem to be in the best interest of the school district.

(b) Any rental of property that complies with subdivision (a) shall be deemed to have thereby required the payment of adequate consideration for purposes of Section 6 of Article XVI of the California Constitution. 
APPENDIX D

Statistics / Costs

For the Next Ten Years

Basic Summary Cost Data for Future School Facilities

\author{
1,000 School districts \\ 10,000 Schools \\ 6,200,000 Students \\ 300,000 Classrooms \\ $100,000,000,000$ Needed over 10 years \\ $50,000,000,000$ Modernization $50 \%$ of work \\ $5,000,000,000 \mathrm{Ea}$ Year for next ten \\ 16,667 Mdnrnztion/yr/class \\ 806 Per student for Modernization costs \\ 30 Students per classroom
}




\section{Interviews}

\begin{tabular}{|c|c|c|c|}
\hline Contact Name & Company & Work Email & Work Phone \\
\hline Chowdhry, Wazi & $\begin{array}{l}\text { San Francisco Unified } \\
\text { School District. }\end{array}$ & ChowdhuryW@sfusd.edu & $\begin{array}{l}415241-6152 \\
\text { X } 1529\end{array}$ \\
\hline Coop, Leigh & Vacaville USD & leighc@vacavilleusd.org & $\begin{array}{l}7074536138 \\
\times 3139\end{array}$ \\
\hline Cowan, Dick & $\begin{array}{l}\text { Cowan Construction } \\
\text { Services }\end{array}$ & dcowan@cowancs.com & 9162174386 \\
\hline Diede, Brett & Diede Construction & $\begin{array}{l}\text { estimating@diedeconstructi } \\
\text { on.com }\end{array}$ & 2093698255 \\
\hline Doerfler, James & Philadelphia University & doerflerj@PhilaU.edu & 215.951 .2700 \\
\hline Dong, Kevin & CalPoly Arch Dept & kdong@calpoly.edu & 8057566465 \\
\hline Flesner, Neal & Ventura Consulting & $\begin{array}{l}\text { neal@venturaconsulting.co } \\
\mathrm{m}\end{array}$ & 8056508040 \\
\hline Forrester , Jim & Antioch USD & $\begin{array}{l}\text { timforrester@antioch.k12.c } \\
\text { a.us }\end{array}$ & $\begin{array}{l}9257797500 \\
\text { ext. } 52000\end{array}$ \\
\hline Fourie, Ferdi & Kiewit Corporation & ferdi.fourie@kiewit.com & 4022712832 \\
\hline Hartung, Bob & $\begin{array}{l}\text { Alternative Delivery } \\
\text { Solutions, LLC }\end{array}$ & adsllc@cox.net & 9493000686 \\
\hline Hopkins, Arlene & $\begin{array}{l}\text { Los Angeles Unified } \\
\text { School District }\end{array}$ & arlene.hopkins@lausd.net & 3103925910 \\
\hline Lawson, Andrew & Severson Werson & jal@severson.com & 4156775539 \\
\hline Leslie, Bruce & Martinez USD & bleslie@martinez.k12.ca.us & $925-335-5927$ \\
\hline Lichtig, Will & Boldt Construction & wlichtig@boldt.com & 9165835617 \\
\hline McFarland, Stephen & Oxnard Union HSD & $\begin{array}{l}\text { stephen.mcfarland@ouhsd. } \\
\text { k12.ca.us }\end{array}$ & $805-385-2518$ \\
\hline Muraco, Mike & Siemens & cerritos office & 7148161472 \\
\hline Nichols, John & HMC Architects & $\begin{array}{l}\text { John.Nichols@hmcarchitec } \\
\text { ts.com }\end{array}$ & 9094184376 \\
\hline Overaa, Carl & Overaa Construction & carl@overaa.com & 5102340926 \\
\hline Salmon, James & $\begin{array}{l}\text { Collab. Constr. } \\
\text { Resources, LLC }\end{array}$ & $\begin{array}{l}\text { james.salmon@collaborativ } \\
\text { ecr.com }\end{array}$ & 5128795050 \\
\hline Savidge, Bill & $\begin{array}{l}\text { Dept of General Services, } \\
\text { OPSC }\end{array}$ & Bill.Savidge@dgs.ca.gov & $916375-4043$ \\
\hline Scott, Kim & Blach Construction & kim.scott@blach.com & 4088698357 \\
\hline Starzyk, Greg & CalPoly CM Dept & gstarzyk@calpoly.edu & 8057562110 \\
\hline Van Gundy, Kim & Fairfield-Suisun USD & $\begin{array}{l}\text { Kim VanGundy } \\
<\text { kimva@fsusd.org> }\end{array}$ & 707 399-5148 \\
\hline Vincent, Jeff & $\begin{array}{l}\text { University of California } \\
\text { Berleley }\end{array}$ & jvincent@berkeley.edu & $510-642-1628$ \\
\hline Wasserman, Mike & $\begin{array}{l}\text { Capital Program } \\
\text { Management }\end{array}$ & mike@capitalpm.com & 9165534400 \\
\hline
\end{tabular}




\section{APPENDIX F \\ Coordination Games, Prisoner's Dilemma and Reputation ${ }^{1}$}

\section{Coordination Games and Non-coordination Games}

Game theory proves for us that cooperation is a successful tactic in the construction industry in two important and specific ways:

Since a construction project is mostly classified as a "coordination game." (one where standards apply, such as building codes) The most successful strategy is a coordinated one, such as uniform adherence to building codes. Communication can help produce a cooperative, coordinated interaction. This is an avenue for leadership. The payoff is greater when strategies are coordinated.

Many games are not coordination games; there is no overriding set of standards applicable to the situation at hand. There is only the outcome dictated by the "rules", or in Game Theory language, "payoffs." Games that are not coordination games, have no immediate avenue for communication. Here, when the parties have a history, and time is of the essence, reputation becomes the operating dynamic for the decision makers.

To be precise, a coordination game is defined by having a payoff always greater when matching the other player's strategy. The best example of a coordination game is choosing which side of the road to drive on. Obviously, "coordinated" strategies are always the best strategies when the conditions of the interaction dictate rigid coordination. In truth, construction interactions are mostly coordination games. Some of the decisions presented to professionals on a construction site arrive absent of background information. At that point, it is reputation of the party presenting the decision that is the prevailing influence on a decision.

One goal of elaborate detail and cooperative engagement in the design phase of a project is to avoid non-coordinated games altogether. As the professionals on site become more and more knowledgeable about the setting of a decision, the more like a coordination game the interaction becomes.

Even if the interaction wasn't contemplated during design and cannot be analyzed under the extraordinary press of time in construction projects, it is the reputation of the parties forms the operative path for decision making.

\section{Prisoner's Dilemma}

Prisoner's Dilemma is not a coordination game. The players have agreed to rules, so it is a "cooperative" game, but there is no communication, only rules. When repeated in

\footnotetext{
${ }^{1}$ Based on: The Evolution of Cooperation Robert Axelrod, Basic Books, New York, 1984
} 
experimental settings, the operative path for decision-making has been shown by Axelrod (1984) to be the reputation of the other player.

The basic set-up is this: Two robbers agree to rob a bank and, if caught, not to testify against each other. So the cooperative choice is to refuse to testify, and the defection is to testify against the partner. They are eventually caught and questioned separately. The police have very poor evidence against them, so the robbers are offered large incentives of reduced penalties for testifying against the other robber. The robbers are not, of course, allowed to communicate; hence this is not a coordination game.

In Prisoner's Dilemma, the payoffs are set by the police, who want the robbers to defect and testify. The police therefore set the payoffs to be much better for defection.

The robbers get off if both cooperate with their original agreement and refuse to rat out their partner, or small sentences if both defect, but five times the sentence for holding out when the other robber defects and testifies. The payoffs (in this case, sentences) are not coordinated. Payoffs are different if the robbers both cooperate or if they both defect.

The discovery of Nash's Equilibrium in this game occurs when the "robbers" play the game over and over, called Iterated Prisoner's Dilemma. In this unrealistic setting, a pattern or "reputation" can be learned by each robber about the other. In construction, this is not so unrealistic. Professionals must interact hundreds of times on any one project.

The strategy analysis in the Iterated Prisoner's Dilemma contains a key observation that can be transferred from Game Theory to actual markets and negotiations. The most successful strategy in the long run is called Tit for Tat. Under this "reciprocity" strategy, there are rules:

1. Never be the first to defect.

2. If the other player defects in any one round, you defect in the next round.

3. Return to Rule \#1.

Reputation is developed quickly and it is the dominant influence in non-cooperation games in the construction industry as well as the proven successful strategy in experimental settings of Iterated Prisoner's Dilemma. 


\section{APPENDIX G \\ ConsensusDocs 300}

\section{Selected Portions}

Attached are 21 pages of the original 47 pages of ConsensusDocs 300.

Refer to Chapter VI, Contracts and Risks.

Used with permission. 


\section{CONSENSUSDOCS 300 \\ STANDARD FORM OF TRI-PARTY AGREEMENT FOR COLLABORATIVE PROJECT DELIVERY}

This document was developed through a collaborative effort of entities representing a wide cross-section of the construction industry. The organizations endorsing this document believe it represents a fair and reasonable consensus among the collaborating parties of allocation of risk and responsibilities in an effort to appropriately balance the critical interests and concerns of all project participants.

These endorsing organizations recognize and understand that users of this document must review and adapt this document to meet their particular needs, the specific requirements of the project, and applicable laws. Users are encouraged to consult legal, insurance and surety advisors before modifying or completing this document. Further information on this document and the perspectives of endorsing organizations is available in the ConsensusDOCS Guidebook.

\section{TABLE OF ARTICLES}

1. AGREEMENT

2. DEFINITIONS

3. COLLABORATIVE PRINCIPLES

4. MANAGEMENT BY THE MANAGEMENT GROUP

5. OWNER PROVIDED INFORMATION

6. DEVELOPMENT OF DESIGN AND COLLABORATIVE PRECONSTRUCTION SERVICES

7. PROJECT PLANNING AND SCHEDULE

8. PROJECT BUDGET, COST MODELING AND PROJECT TARGET COST ESTIMATE

9. DESIGNER'S COMPENSATION

10. CONSTRUCTOR'S COMPENSATION

11. INCENTIVES AND RISK SHARING

12. TRADE CONTRACTORS AND SUBCONTRACTORS

13. CONSTRUCTION OPERATIONS

14. DESIGNER'S CONSTRUCTION PHASE SERVICES

15. TIME

16. DESIGNER'S COMPENSATION AND PAYMENT

17. COST OF WORK

18. PAYMENT

19. RIGHT TO AUDIT

20. CHANGES

21. INDEMNITY, INSURANCE AND BONDS

22. SUSPENSION, NOTICE TO CURE AND TERMINATION OF THE AGREEMENT

23. DISPUTE RESOLUTION

24. MISCELLANEOUS

25. CONTRACT DOCUMENTS

This Agreement has important legal and insurance consequences. Consultation(s) with an attorney and with insurance and surety consultants are encouraged with respect to its completion or modification. 
2.20 The Project Schedule is the document that shows the timing and sequencing of the design and construction required to meet the time criteria set forth in the Owner's Program.

2.21 The Project Target Cost Estimate (PTCE) shall have the meaning ascribed in Paragraph 8.3.

2.22 Responsible Designer shall mean the person or entity that has responsibility for preparing the design, including drawings or specifications, for a particular portion of the Work.

2.23 Services means the services provided by the Designer or by consultants retained by the Designer for the Project.

2.24 A Subcontractor is a person or entity retained by the Constructor as an independent contractor to provide the labor, materials, equipment or services necessary to complete a specific portion of the Work. The term Subcontractor shall include Trade Contractors as defined in Paragraph 2.27. The term Subcontractor does not include the Designer or Others.

2.25 Substantial Completion of the Work, or of a designated portion, occurs on the date when the Work is sufficiently complete in accordance with the Contract Documents so that the Owner may occupy or utilize the Project, or a designated portion, for the use for which it is intended. The issuance of a certificate of occupancy is not a prerequisite for Substantial Completion if the certificate of occupancy cannot be obtained due to factors beyond the Constructor's control. This date shall be confirmed by a Certificate of Substantial Completion signed by the Owner and Constructor.

2.26 A Sub-subcontractor is a person or entity who has an agreement with a Subcontractor to perform any portion of the Subcontractor's Work.

2.27 A Trade Contractor is a person or entity retained by the Constructor to provide collaboration and services during the Preconstruction Phase of the Project. It is anticipated that a Trade Contractor will continue to serve as a Subcontractor during the Construction Phase provided that the Management Group determines that its performance merits continued participation and accepts its price proposal.

2.28 Work means the construction and services necessary or incidental to fulfill the Constructor's obligations for the Project in conformance with this Agreement and the other Contract Documents. The Work may refer to the whole Project or only a part of the Project if work is also being performed by the Owner or Others.

2.28.1 Changed Work means work that is different from the original scope of Work; or work that changes the PTCE or Contract Time.

2.28.2 Defective Work is any portion of the Work that is not in conformance with the Contract Documents.

2.29 Worksite means the geographical area at the location of the Project as identified in Article 1 where the Work is to be performed.

\section{ARTICLE 3 \\ COLLABORATIVE PRINCIPLES}

3.1 OBJECTIVES The Project consists of the design, construction and commissioning of the Project as more fully described in Exhibit A to this Agreement. The Project objectives are to design and construct the facilities called for in the Owner's Program, within the Project Target Cost Estimate and the Schedule developed under the Agreement.

3.2 COLLABORATIVE PROJECT DELIVERY The Parties agree that the Project objectives can be best achieved through a relational contract that promotes and facilitates strategic planning, design, construction and commissioning of the project, through the principles of collaboration and lean project delivery. This approach recognizes that each Party's success is tied directly to the success of all other members of the Collaborative Project 
Team and encourages and requires the Parties to organize and integrate their respective roles, responsibilities and expertise, to identify and align their respective expectations and objectives, to commit to open communications, transparent decision-making, proactive and non-adversarial interaction, problem-solving, the sharing of ideas, to continuously seek to improve the Project planning, design, and construction processes, and to share both the risks and rewards associated with achieving the Project objectives.

3.3 COLLABORATIVE PROJECT DELIVERY TEAM The Parties shall perform as a Collaborative Project Delivery (CPD) Team to facilitate the design, construction and commissioning of the Project. CPD Team members shall share information and collaborate for the benefit of the Project. CPD Team members shall initially include the Owner, the Designer and the Constructor. In forming a Collaborative Project Team, the Parties expect that design consultants and Trade Contractors will be selected to provide preconstruction services early in the preconstruction phase. These parties shall sign Joining Agreements, as they become members of the Team, accepting the principles and methods of collaboration set forth in this Agreement. Ultimate Project decision-making authority shall rest with the Management Group defined in Paragraph 4.1.

3.4 COLLABORATIVE RELATIONSHIP The Parties each accept the relationship of mutual trust, good faith and fair dealing established by this Agreement and covenants with each other to cooperate and exercise their skill and judgment in furthering the interests of the Project. The Designer and Constructor each represents that it possesses the requisite skill, expertise, and, as applicable, licensing to perform the required services. The Owner, Constructor, Designer and all members of the CPD Team agree to adhere to principles of collaboration based on mutual trust, confidence, good faith and fair dealing. Within

the scope of their respective expertise, the Parties shall together actively and continually pursue collaboration in the best interests of the Project The Parties shall endeavor to promote harmony and collaboration among all Project participants.

3.5 OWNER RESPONSIBILITIES The Owner shall work with the Designer and Constructor to identify the Owner's Project objectives, including budget and time criteria, space requirements and relationships, flexibility and expandability requirements, special equipment and systems, and site requirements. The Owner shall provide full information in a timely manner regarding requirements for the Project, including the Owner's Program and other relevant information.

3.6 DESIGNER'S RESPONSIBILITIES The Designer shall furnish or provide all the design and engineering services necessary to design the Project in accordance with the Owner's objectives, as outlined in the Owner's Program and other relevant information defining the Project. Consistent with the collaborative approach set forth in this Agreement, the Designer shall draw upon the assistance of the Constructor and others in developing the Project design, but the Designer shall retain overall responsibility for all design decisions as required by applicable state laws. Cost and schedule are design criteria and the Designer, in collaboration with the CPD Team, shall ensure that design fully considers cost and schedule implications. The Designer represents that it is an independent contractor and that in its performance of the Services it shall act as an independent contractor. The Designer's duties, responsibilities and limitations of authority shall not be restricted, modified or extended without written consent of the Management Group.

3.7 CONSTRUCTOR'S RESPONSIBILITIES The Constructor shall furnish preconstruction and construction administration and management services, collaborate with the Designer in the Designer's development of the Project Plan and Project design and use the Constructor's diligent efforts to promote the delivery of the Project in an expeditious manner. Consistent with the collaborative approach set forth in this Agreement, the Constructor shall assist the Designer in the development of the Project design but shall not provide professional services which constitute the practice of architecture or engineering unless the Constructor needs to provide such services in order to carry out its responsibilities for construction means, methods, techniques, sequences and procedures, or unless such services are specifically called for by the Contract Documents. The Constructor shall provide all labor, materials, equipment and services necessary to complete the Work, all of which shall be provided in full accord with and reasonably inferable from the Contract Documents as being necessary to produce the indicated results. The Constructor shall be responsible for the supervision and coordination of the Work, including the construction means, methods, techniques, sequences and procedures utilized. The Constructor represents that it is an independent Constructor and that in its performance of the Work it shall act as an independent Constructor. The Constructor's 
duties, responsibilities and limitations of authority shall not be restricted, modified or extended without written consent of the Management Group.

\subsection{COLLABORATIVE RISK ALLOCATION}

3.8.1 INTENT The purpose of the Collaborative Project Delivery approach, established by this tri-party relational contract, is to minimize the risk of delay, conflict and increased cost typically experienced by project participants in non-integrated project delivery. By committing to collaborative principles, the Parties affirm their commitment to endeavor to reduce overall risk to the Project and to each participant.

3.8.2 PROJECT RISK ALLOCATION Subject to Article 11, the Parties agree to allocate project risk as follows: (Select One):

_.1 SAFE HARBOR DECISIONS For those Project risks arising from collaboratively reached and mutually agreed-upon Project decisions made by the Management Group (Safe Harbor Decisions), the Parties agree to release each other from any liability at law or in equity for any non-negligent act, omission, mistake or error in judgment, whether negligent or not, acting in good faith, in performing its obligations under this Agreement except to the extent such act or omission amounts to a willful default of an obligation under this Agreement.

.2 TRADITIONAL RISK ALLOCATION Each Party shall be fully liable for its own negligence and breaches of contract and warranty arising from the performance of this Agreement, to the extent provided for under the law of the jurisdiction in which the Project is located, except to the extent as otherwise limited as set forth below: (Indicate Applicable Exception):

a. Limitation on Designer's Liability To the fullest extent permitted by law, and notwithstanding any other provision of this Agreement, the total liability, in the aggregate, of Designer to Owner or Constructor or anyone claiming by, through or under the Owner or Constructor, for any and all claims, losses, costs or damages of whatsoever kind arising out of, resulting from or in any way related to the Project or the Agreement from any cause or causes including but not limited to the negligence or breach of contract of Designer shall not exceed an amount equal to (\$_), unless such claims, losses, costs or damages are reimbursed pursuant to a policy of professional liability insurance maintained by Designer or Designer's Consultants.

b. Limitation on Constructor's Liability To the fullest extent permitted by law, and notwithstanding any other provision of this Agreement, the total liability, in the aggregate, of Constructor to Owner or Designer or anyone claiming by, through or under the Owner or Designer, for any and all claims, losses, costs or damages of whatsoever kind arising out of, resulting from or in any way related to the Project or the Agreement from any cause or causes including but not limited to the negligence, breach of contract or warranty express or implied of Constructor, shall not exceed an amount equal to $\left(\$ \_\right)$, unless such claims, losses, costs or damages are reimbursed pursuant to an insurance policy provided by the Constructor as required by this Agreement.

3.8.3 MUTUAL WAIVER OF CONSEQUENTIAL DAMAGES Regardless of the Project Risk Allocation approach selected by the Parties in Subparagraph 3.8.2, no Party to this Agreement shall be liable to any other Party to this Agreement for consequential damages arising from any cause. The Owner, Designer and Constructor waive Claims against each other for consequential damages arising out of or relating to this Agreement.

3.9 RELIABLE COMMITMENTS Fundamental to the success of Collaborative Project Delivery is the willingness and ability of all CPD Team members to make and secure reliable commitments as the basis for planning and executing the Project. A reliable commitment is one in which the conditions necessary for the satisfaction of the commitment are clear to all parties and the Party making the commitment: 
3.9.1 Is competent and able to perform the task or has retained individuals or entities with the competence or ability to perform the task;

3.9.2 Has estimated the time to perform the task and has allocated adequate resources to perform the task and has properly scheduled time to perform the task;

3.9.3 Has no current basis for believing that the commitment cannot or will not be fulfilled.

3.9.4 Is prepared to be accountable if the commitment cannot be performed as promised and will promptly advise the CPD Team if it believes the task may not be performed as committed.

3.10 QUALITY The Parties acknowledge that quality assurance is critical to the success of Collaborative Project Delivery. Defects or deficiencies in Work or Services negatively impact cost, time, work flow and performance. Those performing the Work or providing the Services must assure quality in the first instance to avoid defects and deficiencies and, when they do occur, proactively and collaboratively mitigate their impact. All Project participants must understand the need to ensure quality at all times.

3.10.1 QUALITY PLAN The Designer and Constructor, in collaboration with the other CPD Team Members, shall develop a plan that, at a minimum, addresses the following issues:

3.10.1.1. Confirming that the Contract-Documents clearly communicated to Project participants the conditions necessary for the satisfaction of the commitment

3.10.1.2. Training workers on the benefits of standardized work practices, the continuous improvement of work practices and the negative impact upon the Project of failing to achieve commitments

3.10.1.3 Using mockups, first run studies, early completion of standard work units, and similar efforts to demonstrate and document agreed-upon levels of quality

3.10.1.4 Using permit processes to identify and enhance quality initiatives

3.10.1.5 Providing task-based quality checklists for use by trade persons to self-evaluate quality performance, establish benchmarks and promote continuous improvement

3.10.1.6 Developing methods for onsite managers and others providing quality assurance to review early work product and assure quality performance

3.10.1.7 Integrating quality review and Project planning and scheduling pursuant to Article 7

3.10.1.8 Developing protocols for trade persons to discuss and assure quality when work is being handed off to another

3.10.1.9 Identifying procedures for immediately addressing quality failures by workers originally performing work, to assure minimum cost impact and continuous improvement

3.10.1.10 Developing procedures for recognizing outstanding performance and quality by individual trade persons and the Parties

3.10.1.11 Creating standards by which to measure and track quality performance.

\section{ARTICLE 4 \\ MANAGEMENT BY THE MANAGEMENT GROUP}


4.1 MANAGEMENT GROUP The delivery of the Project shall be managed by the Management Group, which shall serve as the decision-making body for the delivery of the Project and shall employ collaborative methods for achieving the highest quality and most efficient and economical delivery of the Project. The Management Group shall be comprised of an authorized representative of the Owner, the Designer and the Constructor. The original Management Group may invite other critical project participants to become members of the Management Group, for purposes of advancing the overall collaborative approach and the best interests of the Project. Any party added as an additional Management Group member shall be entitled to participate in all Management Group functions and shall have a right to vote on Management Group decisions that directly concern that party's work and area of expertise. The Management Group may also vote to remove non-original Management Group members from the Management Group.

4.2 OWNER'S MANAGEMENT REPRESENTATIVE The Owner's authorized Management Group representative is who shall be fully acquainted with the Project, and shall have authority to bind the Owner in all matters requiring the Owner's approval, authorization or written notice. The Owner's alternative representative shall be

4.3 DESIGNER'S MANAGEMENT REPRESENTATIVE The Designer's authorized Management Group representative is __ who shall possess full authority to bind the Designer in all matters requiring the Designer's approval, authorization or written notice. The Designer's alternative representative shall be

4.4 CONSTRUCTOR'S MANAGEMENT REPRESENTATIVE The Constructor's authorized Management Group representative is _. who shall possess full authority to bind the Constructor in all matters requiring the Constructor's approval, authorization or written notice. The Constructor's alternative representative shall be

4.5 REPLACEMENT OF MANAGEMENT GROUP MEMBERS Any Party may, upon seven (7) Days' written notice appoint a new authorized representative to the Management Group, provided no other Party has a reasonable objection to the proposed replacement.

4.6 DECISION-MAKING Consistent with the principles of collaboration, the actions and decisions of the Management Group shall, to the greatest extent possible, be by consensus, and the members of the Management Group shall endeavor to reach decisions by consensus. The Management Group shall act in the best interest of the Project as a whole without consideration to each member's own interest, and consistent with applicable laws, codes and regulations. To the extent consensus cannot be reached among the three original Management Group members, the Owner shall make a determination in the best interest of the Project as a whole subject to the dispute resolution process in Article 23. Decisions implicating life, health, property and public welfare and which are required to be made by a licensed design professional, shall be made by the Designer in accordance with Paragraph 3.6.

\subsection{MANAGEMENT GROUP MEETINGS}

4.7.1 INITIAL MEETING Following execution of this Agreement, the Management Group shall have an initial meeting to review the Owner's Program and establish the Management Group's goals for the Project and to begin initial Project planning. If no Owner's Program has been established, the Management Group shall meet for the purpose of assisting the Owner in the development of an Owner's Program.

4.7.2 REGULAR MEETINGS The Management Group shall establish a schedule for regular meetings for the purpose of reviewing and discussing the Project status and any issues impacting the progress of the Project including conflicts, delays, and their causes and potential claims.

4.7.3 SPECIAL MEETINGS In the event a Project matter arises requiring immediate attention, any member of the Management Group may call for a meeting on one (1) Day's written notice. Such notice shall include a thorough description of the issues to be addressed. Special Meetings may be conducted through any medium the Management Group members mutually agree upon, including telephone, video or webconferencing. 
4.8 CPD TEAM MEETINGS The Management Group shall establish a matrix for regular meetings of the CPD Team. This matrix shall include meetings for overall Project planning and weekly project scheduling and coordination, variance meetings, as well as the record-keeping and reporting requirements for such meetings.

4.9 PRINCIPLES OF COMMUNICATIONS The Parties acknowledge that a truly collaborative relationship requires consistently open, honest and clear verbal and written communications that completely and accurately convey all Project issues, conflicts, deliverables and reliable commitments to perform obligations as promised, and the Parties shall endeavor at all times to so communicate.

4.9.1 COMMUNICATIONS PROTOCOL The Management Group shall meet, confer and agree upon a written protocol for all forms of Project communications, including Project meetings, written and electronic communications. The protocol shall:

\subsubsection{Identify critical Project personnel and their contact information;}

4.9.1.2 Provide a detailed project meeting matrix with attendance requirements;

4.9.1.3 With the goal that there be no offline Project-related discussions among Project participants, allow for direct communication between specialty subcontractors and design consultants and the Owner, Constructor or Designer, as necessary, with contemporaneous notification of the context of such communication to the other parties;

4.9.1.4 Establish a further protocol for the exchange of electronic Project documentation. The failure of a Party to adhere to the Project communications protocol shall be a breach of this Agreement, grounds for withholding payment and a basis for termination as provided elsewhere in this Agreement.

4.9.2 ELECTRONIC COMMUNICATION PROTOCOL The Parties may use electronic documentation transmitted or made available through various means including e-mail, a Project based website, FTP sites or other available methods. The Management Group shall develop a protocol for the exchange of electronic communications to be adhered to by all Project participants.

The Electronic Communication Protocol shall at a minimum:

4.9.2.1 Identify one Party to manage the exchange process, including responsibility for providing and coordinating notifications;

4.9.2.2 Identify an individual or individuals within each firm or company responsible for compliance with document exchange protocols;

4.9.2.3 Define the documents to be accepted in electronic form or transmitted electronically, including a specific listing of such documents for the project (e.g., drawings, shop drawings, change orders, requests for information, etc);

4.9.2.4 Set forth the Parties' listing of, and responsibilities for compliance with, equipment, software and services impacting the transmission, receipt or utilization of electronic documents and data (including any prohibitions on or cautions as to utilization of different operating systems or translation programs and any equipment and software upgrading expectations);

4.9.2.5 Document transmission standards, such as acceptable formats, transmission methods and verification procedures;

4.9.2.6 Identify third-party providers, if any, with copies of governing agreements/licenses;

4.9.2.7 Identify methods for maintaining version control of electronic documents, including a depository of record copies of transmitted and received electronic documents; 
4.9.2.8 Specify privacy and security requirements;

4.9.2.9 Set forth storage and retrieval requirements for electronic documents and data.

4.10 PROJECT PERSONNEL The Designer and Constructor have each designated as their key Project personnel those individuals identified in Exhibit B to this Agreement. Neither the Designer nor the Constructor shall remove or replace any of its key Project personnel without the Management Group's prior written consent. Any replacement personnel shall have substantially equivalent or better qualifications than the employee being replaced.

4.10.1 The Management Group shall not have any duties of supervision or control of any person employed or retained by the Designer, the Constructor, or their respective subconsultants, subcontractors and
suppliers in connection with the Project.

4.10.2 The Designer and the Constructor shall remove from the Project any employee or person retained by it for the Project to which the Owner or Management Group has a reasonable objection.

\section{ARTICLE 5 \\ OWNER PROVIDED INFORMATION}

5.1 SITE INVESTIGATION PLAN The Management Group shall jointly develop a preconstruction site investigation plan identifying additional needed preconstruction information and investigations at or concerning the site. The Management Group shall also identify in writing any apparent deficiencies or discrepancies in the information Owner provides. As part of this process, the Designer and Constructor shall describe and advise Owner of additional investigations or information reasonably required to prepare the Construction Documents.

5.2 OWNER INFORMATION Preconstruction information to be provided by the Owner should include:

5.2.1 information describing the physical characteristics of the site, including surveys, site evaluations, legal descriptions, data or drawings depicting existing conditions, subsurface conditions and environmental studies, reports and investigations;

5.2.2 tests, inspections and other reports dealing with environmental matters, Hazardous Material and other existing conditions, including structural, mechanical and chemical tests, required by the Management Group
or by law; and

5.2.3 any other information or services requested in writing by the Management Group which are relevant to the planning, design and construction of the Project.

5.2.4 Budget information regarding the Project for design, construction and Owner-provided items. The Management Group shall jointly manage the budget to further the Project objectives. The information required shall be provided in a timely manner and in reasonable detail. Legal descriptions shall include easements, title restrictions, boundaries, and zoning restrictions. Worksite descriptions shall include existing buildings and other construction and all other pertinent site conditions. Adjacent property descriptions shall include structures, streets, sidewalks, alleys, and other features relevant to the Work. Utility details shall include available services, lines at the Worksite and adjacent thereto and connection points. The information shall include public and private information, subsurface information, grades, contours, and elevations, drainage data, exact locations and dimensions, and benchmarks that can be used by the Constructor in laying out the Work.

5.3 ACCESS TO PRECONSTRUCTION INFORMATION To the extent that preconstruction information exists, the Management Group shall provide prospective Project participants access to the information with reasonable promptness, and without cost or expense. CPD Team members shall review the information furnished with reasonable care and advise the Management Group in writing of any errors, inconsistencies, inaccuracies, or 
incompleteness which would prompt Constructor, Trade Contractors or Subcontractors to include additional contingency in their estimates or require a Responsible Designer to make a design assumption that might prove wasteful if additional investigation was performed. The CPD Team member shall also suggest options for additional preconstruction investigation of existing conditions for Management Group consideration, including the cost and potential benefit of the differing levels of potential preconstruction investigation.

5.3.1 A CPD Team member that has fulfilled its obligations under Paragraph 5.3 shall be entitled to rely upon the accuracy of the information provided to the extent that it is not contradicted by the Contract Documents.

5.4 Designer shall be responsible for coordinating the information provided by Owner, Owner's consultants and Designer's consultants to prepare coordinated design documents pursuant to this Agreement.

\section{ARTICLE 6 \\ DEVELOPMENT OF DESIGN AND COLLABORATIVE PRECONSTRUCTION SERVICES}

6.1 COLLABORATIVE DESIGN PRINCIPLES In order to achieve the Project objectives, the design process must occur in a collaborative manner, informed by a free-flow of accurate information concerning program, quality, cost and schedule. While retaining overall responsibility for the Project design, the Designer must work collaboratively with the other members of CPD Team, drawing on their respective expertise in order to achieve the Project objectives.

6.2 SCOPE A description of the scope of services to be provided by Designer and Designer's consultants and the documents to be developed during each phase or progression of the design is set forth in Exhibit C. The Management Group shall oversee development of the design documents for the Project and develop milestone schedules for the preconstruction phase.

6.3 INFORMATION In accordance with Article 5, Owner shall provide full information regarding requirements for the Project including a Program which shall set forth Owner's design objectives, constraints and criteria, including space requirements and relationships, flexibility and expandability, special equipment and systems and site requirements.

6.4 LAWS AND REGULATIONS Design Services shall comply with all applicable laws and requirements in effect during the preparation of the Contract Documents and any governmental authority from whom permits, approvals or other consents for the Project may be required. A Responsible Designer shall identify and determine the meaning and effect of all applicable building code provisions and other applicable laws, requirements and restrictions, whether or not listed in the Contract Documents, and take such measures as may be necessary to meet such laws or requirements, including filing or revising any required applications, drawings, specifications, calculations or other documents to the extent necessary to secure any required permits, approvals or other consents for construction of the Project at the Project site. Owner shall pay all costs and fees required to secure necessary permits, approvals and other consents.

6.5 PULL BASED DESIGN The Designer shall use "pull based" planning principles to develop the Design Documents. Pull based design advances the design only so far as has been anticipated and approved for any given time period by the Management Group, with the designers only performing services that are shown on the applicable Project plan as being performed in that week or that has been identified as "workable backlog." If rework is required as a result of failure to conform to the approved plan, the Party failing to adhere to that approved plan shall be responsible for all resulting costs associated with rework.

6.6 Consistent with the collaborative approach set forth in this Agreement, should the Constructor, Trade Contractors or Subcontractors in the course of the performance of obligations discover any errors, omissions or inconsistencies in the design documents prepared by the Designer or Responsible Designers, they shall promptly notify the Management Group, for action by the Designer. It is recognized that the Constructor, Trade Contractor and Subcontractor are not acting in the capacity of a licensed design professional. 
6.7 DESIGN-BUILD WORK The Management Group shall specify all applicable performance and design criteria for any work that is performed on a design-build basis. The Constructor shall retain appropriately licensed design professionals to provide all design services related to the Design-Build Work. Limitations on Constructor's responsibility for design stated elsewhere in the Contract Documents shall be inapplicable to Design-Build Work.

6.8 DESIGN DOCUMENT STANDARDS The Management Group shall specify the standards to which all design documents shall comply.

6.9 BUILDING INFORMATION MODELING APPROACH The Parties may establish a building information modeling (BIM) approach to design and construction of the Project, providing continuous and immediate availability of reliable, integrated and coordinated design, scope, schedule and cost information. The use of a building modeling approach, and the processes and technologies necessary to fully utilize such an approach, shall be established as an addendum to this Agreement. If a BIM approach is elected, the Management Group shall establish the BIM parameters, standards and technological requirements.

\subsection{OWNERSHIP AND USE OF DOCUMENTS}

6.10.1 All drawings, plans, specifications, calculations, notations and other documents prepared by Designer, Subconsultants, Constructor, Subcontractors or other CPD Team members in connection with the Project (and any electronic media upon which they were prepared or stored) (the "Project Documents"), including, without limitation, the Design Development Documents and the Construction Documents, are prepared for the Owner, and all title, ownership, and copyright privileges are and at all times shall be vested in Owner, subject only to the use provisions set forth below.

6.10.2. The originals of all Project Documents shall be held by CPD Team Members for the benefit of Owner. At Owner's request and cost, any or all Project Documents shall be immediately delivered to Owner in their original form, or in clear, reproducible form, regardless of whether this Agreement is completed,
suspended or terminated.

6.10.3 OWNER'S USE Provided Owner has paid Designer in accordance with the terms of this Agreement, Owner shall have the right, regardless of whether this Agreement is completed, suspended or terminated, in whole or in part, to use and reuse the Project Documents for any purpose. In the event Owner uses or reuses the Project Documents to perform work or have work performed on its behalf for which a CPD Team Member who authored the documents is not retained, Owner shall indemnify, protect and hold that CPD Team Member free and harmless from liability, if any, arising from the use of any Project Documents by Owner, including, without limitation, any liability to third parties for personal injury, death, or property damage.

6.10.4 AUTHOR'S USE The author of a Project Document may reuse plans, drawings, specifications and other data prepared pursuant to this Agreement in its practice, but only in their separate constituent parts and not as a whole. In the event any Party uses any of the plans, drawings, specifications and other data in its practice, that Party shall indemnify, protect and hold Owner free and harmless from liability, if any, arising from the use of such plans, drawings, specifications and other data, including, without limitation, any liability to third parties for personal injury, death, or property damage.

6.10.5 LIMITED USE BY NON-AUTHOR Subject to Subparagraph 6.10.4, the Project Documents, together with submittals or other design documents prepared by Constructor, or any Subcontractor, Material Supplier, or Sub-subcontractor specifically for this Project, and copies thereof furnished to Constructor, are for use solely with respect to this Project. They are not to be used by Constructor, Subcontractors, Subsubcontractors or Material Suppliers on other projects, outside the scope of the Work, without the specific written consent of Owner. Constructor, Subcontractors, Sub-subcontractors and Material Suppliers are granted a limited license to use and reproduce applicable portions of the Project Documents appropriate to and for use in the execution of their Work under the Contract Documents. 
6.11 OWNER APPROVAL All approvals required from Owner shall be in writing. Owner approval shall not constitute a waiver by Owner of any of its rights under this Agreement, nor shall it relieve Designer or Designer's consultants from any of their obligations or liability for the technical or professional adequacy of their Services.

6.12 TEAM MEETING During the Preconstruction Phase, the Management Group shall meet every other week and shall schedule regular weekly meetings for the CPD Team, to facilitate collaboration regarding all project elements, including site use and improvements, the selection of materials, building systems, and equipment.

\subsection{TARGET VALUE DESIGN}

6.13.1 TARGET VALUE DESIGN SUPPORT The Constructor and Trade Contractors shall provide Target Value Design support during the development of the Project design, as more fully discussed in Article 8. Target Value Design support is intended to inform the overall Project design with the critical criteria of quality, cost, schedule and constructability.

6.13.2 The Management Group shall develop Target Value Design methods for the Designer, Constructor and Trade Contractors, addressing the establishment of initial target costs for major Project components and systems; the selection of Trade Contractors; the formation and conduct of Project design, supply and construction teams for major Project components and systems; and cost analysis procedures.

6.14 VALUE IDENTIFICATION AND CREATION Throughout the development of the Project design, the Designer, its consultants, Constructor and its Subcontractors and Material Suppliers shall continually seek to create value by identifying options to improve constructability and functionality, reduce capital or life cycle cost, or provide operational flexibility consistent with the Owner's programmatic needs. As part of those efforts, the Designer, its consultants, Constructor, its Subcontractors and Material Suppliers shall identify and evaluate alternative systems, means, methods, configurations, finishes, equipment and approaches that will create a savings of time or money in constructing or operating and maintaining the Project, or increase quality, constructability, or other measures of value. As a result of these efforts, a CPD Team member may submit a Value Creation Proposal to the Management Group that details the proposed change, identify all aspects of the Project directly or indirectly affected by the change, specify the cost or time savings to be achieved if the proposal is accepted, and detail any anticipated effect on the Project's service life, economy of operation, ease of maintenance, appearance, design or safety standards. The Management Group shall determine whether to pursue a Value Creation Proposal. If a Value Creation Proposal is adopted, the Designer shall ascertain design feasibility, consistency with the Owner's programmatic needs, compatibility and compliance with building regulations, and professional standards of care and incorporate the proposed value creation into the Project design and Contract Documents.

6.15 CONSTRUCTABILITY Throughout the development of the Project design, Constructor shall conduct constructability reviews in collaboration with the Designer, to determine that the design documents will result in construction drawings that are sufficiently complete, accurate and coordinated so as to reduce the risk of disruption, delay, change orders and potential claims. The findings of these reviews shall be recorded and distributed to all CPD Team Members. The Designer shall evaluate the findings of these reviews and as appropriate incorporate changes in the design documents, provide notations on the Construction Documents or explain why such action is unnecessary. In conducting constructability reviews, the Constructor shall not provide professional services which constitute the practice of architecture or engineering. Designer is responsible for the completeness and accuracy of the design. Notwithstanding the foregoing, consistent with the collaborative approach set forth in this Agreement, the Constructor shall advise the Designer if Constructor is actually aware that the design does not comply with codes, laws or requirements of government or public authorities having jurisdiction over the Project. Nothing in this section shall relieve any Party from their respective obligations to perform in accordance with the terms of their respective contract and the applicable standard of care.

6.16 REQUESTS FOR INFORMATION The CPD Team members shall have as their goal the elimination of the need for requests for information through effective collaboration and communication during preconstruction in order to maximize the Parties' understanding of the design requirements, including the design intent and all technical requirements of the Project, prior to construction. To the extent requests for information are necessary, the Party seeking clarification shall first address the issue through direct discussions among appropriate Project personnel, and thereafter as necessary through senior party representatives. The resolution of issues, or the failure to achieve 
resolution, shall be documented and reported to the Management Group. Absent an agreement or direction to the contrary by the Management Group, clarifications shall be issued no more than five (5) business Days after receipt of a request for interpretation, including requests received via telephone. Interpretations and decisions of the Designer will be consistent with the intent of and reasonably inferable from the Contract Documents and will be in writing or in the form of drawings.

\section{ARTICLE 7 PROJECT PLANNING AND SCHEDULE}

7.1 PRELIMINARY PLANNING The Designer and Constructor shall each review the Owner's Program to ascertain the requirements of the Project. The Designer and Constructor, together with any Trade Contractors then retained, shall meet to confer on and verify such requirements. The Designer and Constructor shall provide to the Management Group for its written approval a joint preliminary evaluation of the Owner's Program and the Project requirements, addressing all issues bearing upon the success of the Project including the need for additional study or of testing, the site with regard to access, traffic, drainage, parking, building placement and other considerations affecting the building, the environment and energy use, as well as information regarding applicable governmental laws, regulations and requirements. The joint preliminary evaluation shall also propose alternative architectural, civil, structural, mechanical, electrical and other systems for review by the Management Group, to determine the most desirable approach on the basis of cost, technology, quality and speed of delivery. The Designer and Constructor shall also review existing test reports but will not undertake any independent testing nor be required to furnish types of information derived from such testing in their joint preliminary evaluation. The joint preliminary evaluation shall specifically identify any deviations from the Owner's Program.

7.2 PROJECT PLANNING SYSTEM The CPD Team shall employ a system of project planning that includes the collaborative development of a milestone schedule, phase or progression schedules, "make-ready" look ahead plans, weekly work plans and methods for recording, measuring and improving the reliability of project planning.

7.2.1 PULL PLANNING The Project shall employ a pull scheduling approach to planning and scheduling, which provides that preceding activities are not started sooner than is needed to assure the continuous performance of subsequent activities. Where the work of one Team member is dependent upon the prior performance of another Team member, the Team member whose work follows shall request of and receive from the prior performer a commitment as to when the work to be handed-off will be finished and the Team members shall agree upon criteria for the hand-off of work.

7.2.2 PHASE PLANNING Project Planning shall be based on the collaborative efforts of all those performing work during a given period and shall indicate when work will be done to meet milestone dates.

7.2.3 MAKE-READY LOOK AHEAD PLAN Make-Ready Look Ahead plans shall be developed by the CPD Team, identifying each item of work to be performed and completed during the given planning period, whether factors exist that would impede performance and completion and the actions to be taken to negate any such impediments.

7.2.4 WEEKLY CPD TEAM MEETINGS The CPD Team shall conduct weekly meetings to review and evaluate work to be performed in the coming week and any factors that might impede the completion of work.

\subsection{SCHEDULE}

7.3.1 PROJECT SCHEDULE The Designer and Constructor, based on input from other CPD Team members, shall jointly prepare for the Management Group's review and approval a Milestone Schedule that shall show the timing and sequencing of the design and construction required to meet the time criteria set forth in the Owner's Program. The Milestone Schedule shall be updated for the Management Group's review and approval at such intervals required by the Management Group as appropriate for a BIM approach, or in the absence of such, at the completion of Schematic Design Documents, Design 
Development Documents and Construction Documents, except when construction commences before the completion of such documents. If any Milestone Schedule shows a deviation from previously approved Project Schedules, the Designer and Constructor shall make appropriate recommendations to the Management Group.

7.3.2 CONSTRUCTION SCHEDULE When Project requirements have been sufficiently identified, the Constructor shall prepare a preliminary Construction Schedule for the review and approval of the Management Group. The Construction Schedule shall coordinate and integrate the services and activities of the Owner, Constructor, Designer, Subcontractors and the requirements of governmental entities. As design proceeds and at appropriate intervals the Constructor shall update the Construction Schedule, for the Management Group's approval, to indicate proposed activity sequences, durations, or milestone dates for such activities as receipt and approval of pertinent information, issuance of the Construction Documents, the preparation and processing of shop drawings and samples, delivery of materials or equipment requiring long-lead time procurement, Owner's occupancy requirements and estimated date of Substantial Completion of the Project. If Construction Schedule updates indicate that milestone dates contained in prior Construction Schedules will not be met, the Constructor shall notify and make recommendations to the Management Group. If the Project is to be completed in phases, the Designer and the Constructor shall make recommendations to the Management Group regarding the phased issuance of Construction Documents.

7.3.3 The Constructor Team shall monitor the performance of Subcontractors as it relates to the Construction Schedule; update the Construction Schedule and if required, recommend corrective alternatives or adjustments to the Management Group.

\section{ARTICLE 8 \\ CONSTRUCTION BUDGET AND COST MODELING AND CONSTRUCTION CONTROL ESTIMATE}

\subsection{BUDGETS}

8.1.1 OWNER'S PROJECT BUDGET Based on the information then available to the Owner, at the beginning of the Project the Owner shall provide to the Management Group a Project Budget estimating the total cost to achieve the design and construction of the Owner's Program. The Project Budget cannot be revised without Owner approval, which approval may not be given.

8.1.1.1 The Designer and Constructor shall review and critique the Project Budget. Based on such review, the Owner may revise the Project Budget.

8.1.2 DESIGN BUDGET At the beginning of the Project, the Designer, in collaboration with the Owner and Constructor, shall develop a Design Budget, which shall include an estimate of all design costs and designrelated expenses and the Designer's Fee.

8.1.3 CONSTRUCTION BUDGET At the beginning of the Project, the Constructor shall, with the collaboration and assistance of the Management Group, establish a Construction Budget, which shall
include:

8.1.3.1 A preliminary estimate of the total cost for construction;

8.1.3.2 A Design Contingency to cover increases in estimated construction costs as a result of the refinement or further development of the design, but not changes in the overall scope of the work;

8.1.3.3 A Construction Contingency to cover costs which are properly reimbursable as a Cost of the Work but are not the basis for a Change Order. 


\subsubsection{Contingencies to cover costs for securing bids and material price escalations;}

\subsubsection{Allowances and a statement of their basis; and}

8.1.3.6 The Constructor's Fee. Based on information provided by the Owner, the Construction Budget shall include the cost of labor, materials or equipment associated with Owner-supplied equipment for the Project, whether installed by the Constructor or others. The Construction Budget shall not include compensation for the Designer or the costs of land, rights of way, financing or other items for which Owner is responsible.

8.1.4 The CPD Team shall use diligent efforts to design the Project so that it may be constructed without exceeding the Construction Budget. The Construction Budget cannot be revised without Owner approval, which approval may not be given.

8.1.5 TARGET VALUE PRICING The Constructor and Trade Contractors shall provide Target Value Design support services to support the explicit premise that value, cost, schedule and constructability are basic components of the design criteria. Those efforts shall include Target Value Pricing, which involves ongoing cost information and estimates of portions of the Work, systems under consideration and such other cost information as required by the Management Group. Target Value Pricing shall include the development of the cost models described in Paragraph 8.2 but shall be on-going and not await the completion of the various stages of design development.

8.2 COST MODELING The Constructor shall provide on-going cost modeling to inform and promote its Target Value Design efforts and those of Trade Contractors, as described in this article and Article 6 . The Constructor shall generate cost model reports at such times and in such manner as described herein, or as otherwise direct by the Management Group. If a BIM approach to design and construction of the Project is being utilized, then cost model reports shall be generated at appropriate milestones as designated by the Management Group.

8.2.1 PRELIMINARY COST MODEL When Project requirements and design concepts have been sufficiently developed, as determined by the Management Group, the Constructor, with the assistance of and in collaboration with Trade Contractors, the Owner and Designer, shall prepare a Preliminary Cost Model. The Preliminary Cost Model shall employ utilizing area, volume or similar conceptual estimating techniques, and shall identify all of the major building systems, the quantity and unit cost (or cost per square foot) of each work item, a summary of anticipated construction costs for each part of the Project, and all major assumptions underlying pricing. The Preliminary Cost Model shall be reviewed and approved by the Management Group, and thereafter provide the foundation for Target Value Design efforts.

8.2.2 SCHEMATIC DESIGN COST MODEL In the absence of a BIM approach, when the Designer has prepared and completed Schematic Design Documents, the Constructor, with the assistance of Trade Contractors, shall update the Preliminary Cost Model and submit a Schematic Design Cost Model to the Management Group for its review and approval.

8.2.3 DESIGN DEVELOPMENT COST MODEL In the absence of a BIM approach, when the Designer has prepared and completed Design Development Documents, the Constructor, with the assistance of Trade Contractors, shall update the Schematic Design Cost Model and submit a Design Development Cost Model to the Management Group for its review and approval.

8.2.4 CONSTRUCTION DOCUMENT COST MODEL In the absence of a BIM approach, when the Designer's completion of Construction Documents reaches approximately fifty percent (50\%) the Constructor, with the assistance of Trade Contractors, shall update the Design Development Cost Model and submit a Construction Documents Cost Model to the Management Group for its review and approval.

8.2.5 ESTIMATED COST OF THE WORK When the Construction Documents reach one hundred percent $(100 \%)$ completion, the Constructor shall, with the assistance of Trade Contractors, prepare an Estimate of the Cost of the Work in such detail and in such format as required by the Management Group. The Estimate of the Cost of the Work shall provide the basis for the development of the PTCE. 
8.2.6 CONTINGENCIES IN COST MODELS Cost models prepared by the Constructor may contain Construction Phase, Escalation and Permitting contingencies as approved by the Management Group.

8.2.7 COST MODEL RECONCILIATION Cost models shall be reviewed on an ongoing basis to determine if the models conform to approved budgets and target costs developed as part of Target Value Design efforts. To the extent cost models do not conform with budgets and target costs, the Management Group shall give direction on what actions shall be taken by members of the CPD Team.

8.2.8 ACCOUNTING RECORDS The Constructor and Trade Contractors shall maintain cost accounting records on Work performed under unit costs, actual costs for labor and materials, or other similar methods; afford the Management Group access to these records; and preserve them for a period of three (3) years after final payment.

\subsection{PROJECT TARGET COST ESTIMATE}

8.3.1 PROJECT TARGET COST ESTIMATE At such time as the Management Group determines that the project design is sufficiently complete, the Owner, Designer and Constructor shall jointly develop a Project Target Cost Estimate (PTCE) in a format acceptable to the Management Group. Unless the Parties mutually agree otherwise, the Project Target Cost Estimate shall be the sum of:

8.3.1.1 The Owner's own Project design and construction-related costs, as agreed upon by the Parties;

\subsubsection{The Designer's total costs for Project design and design implementation;}

8.3.1.3 The Constructor's construction costs, including:

.a the estimated Cost of the Work

.b A Construction Phase Contingency to cover costs which are properly reimbursable as a

Cost of the Work but are not the basis for a Change Order.

.c A Design Contingency if the drawings and specifications are not complete;

.d A Permitting contingency to address changes required by permitting agencies;

.e Allowances and a statement of their basis;

f General Conditions; and

.g The Constructor's Fee.

\subsubsection{CONTINGENCIES}

8.3.2.1 FURTHER DESIGN DEVELOPMENT If the drawings and specifications are not complete at the time the PTCE is developed and submitted to the Management Group, the PTCE shall provide for final development of the design documents. Such further development does not include changes in scope, systems, kinds and quality of materials, finishes or equipment, all of which if required, shall be incorporated by Change Order.

8.3.2.2 PERMIT CONTINGENCY Subject to the approval of the Management Group, the PTCE shall include a contingency to cover any changes in the requirements of permitting agencies as part of their approval of Construction Documents.

8.3.2.3 CONSTRUCTION CONTINGENCY The PTCE shall include a contingency for all additional Costs of the Work that may be incurred by Constructor, Trade Contractors or Subcontractors during construction that do not provide the basis for a Change Order. The Constructor's use of this contingency shall be subject to the prior approval of the Management Group. Unused contingency funds shall be used to fund the incentive programs described in Article 11.

8.3.3 BASIS OF PROJECT TARGET COSTS ESTIMATE The PTCE shall include a written statement of its basis, which shall include: 
8.3.3.1 a list of the drawings and specifications, including all addenda, which were used in preparation of the PTCE;

\subsubsection{2 a list of allowances and a statement of their basis;}

8.3.3.3 a list of the assumptions and clarifications made in the preparation of the PTCE to supplement the information contained in the drawings and specifications;

8.3.3.4 the Date of Substantial Completion or the Date of Final Completion upon which the proposed PTCE is based, and the Schedule of Work upon which the Date of Substantial Completion or the Date of Final Completion is based;

8.3.3.5 a schedule of applicable alternate prices;

8.3.3.6 a schedule of applicable unit prices;

8.3.3.7 a statement of Additional Services included, if any;

\subsubsection{8 the Constructor's Construction Contingency;}

\subsubsection{9 the Design Contingency;}

8.3.3.10 a statement identifying any patented or copyrighted materials, methods or systems incorporated in the Work that are likely to require the payment of royalties or license fees;

8.3.3.11 a statement of the estimated cost and a schedule of values organized by trade categories, allowances, contingencies permitted by this Agreement, self-performed work, and other items and the fee that comprise the PTCE; and

8.3.3.12 A detailed budget and breakdown of all General Conditions and jobsite management expenses included within the PTCE.

8.3.4 REVIEW AND ADJUSTMENT TO PTCE The Management Group shall meet to review the PTCE. In the event that the Management Group has any comments relative to the PTCE Proposal, or finds any inconsistencies or inaccuracies in the information presented, it shall give prompt written notice of such comments or findings to the Parties, who shall make appropriate adjustments to the PTCE, its basis or both. 8.3.5 PTCE PROPOSAL EXCEEDS CONSTRUCTION BUDGET If the PTCE Proposal exceeds the Project
Budget:

8.3.5.1 The Owner may give written approval to increase the Project Budget;

8.3.5.2 The Management Group may authorize rebidding or renegotiating all or any portion of the Project, within such time period as required by the Management Group;

8.3.5.3 The Management Group may direct the CPD Team to collaborate on revising the Project scope to bring it within the Project Budget, and the Designer, as necessary, shall revise the drawings and specifications to allow the PTCE to be reduced to one hundred percent (100\%) of the Project Budget;

8.3.5.4 The Owner may elect to terminate the Project. If the Management Group determines that changes in market conditions or other conditions beyond the control of the CPD Team are the cause for the PTCE Proposal exceeding the Project Budget, the Management Group may authorize reimbursement for such services from applicable contingency funds. 
8.3.6 ACCEPTANCE OF CONSTRUCTION CONTROL ESTIMATE PROPOSAL Upon acceptance by the Management Group of the PTCE, the PTCE and its basis shall be set forth in Amendment No. 1. The PTCE shall be subject to adjustment as provided in this Agreement.

8.3.7 LIMITATION ON CHANGES Subject to its right to access the contingencies, Constructor shall use its diligent efforts to complete the Project for the compensation stated in the PTCE. Based on its collaboration in the preconstruction phase of the Project, the Constructor agrees that it shall not be entitled to an increase in the PTCE for work that Constructor or any other CPD Team Member might otherwise claim as a Change Order or extra work unless the change is the result of: (a) material change in the scope of work; (b) a change required by regulatory authorities (including inspections) that was not reasonably ascertainable from the Contract Documents; (c) Differing Site Conditions; (d) a Compensable Delay; or (e) a claim for which the Owner is found liable. Nothing in this paragraph shall preclude Constructor from using the contingencies for properly incurred Costs of the Work that are attributable to causes for which a change order is prohibited by this paragraph.

\section{ARTICLE 9 \\ DESIGNER'S COMPENSATION}

\subsection{COMPENSATION FOR BASIC SERVICES}

9.1.1 For Basic Services, the Owner shall compensate the Designer on the following basis, including applicable sales taxes (indicate applicable options):

_.1 The actual cost of the following:

a. Designer's personnel as listed in Exhibit B.

b. Services of consultants and subcontractors at a multiple of amount billed to the Designer for such services.

c. Reimbursable Expenses incurred in connection with Basic Services, as described by exhibit to this Agreement, at their actual cost.

_.2 The Designer's Fee paid in proportion to the Services performed subject to adjustment as provided in Subparagraph 9.1.3. The Designer's Fee shall cover normal, non-Project overhead and normal profit. The Designer's compensation to be paid shall be limited by the PTCE established in Amendment No. 1, as the PTCE may be adjusted, and subject to the incentive and risk sharing provisions of Article 11.

9.1.2 DESIGNER'S FEE The Designer's Fee shall be comprised of normal, non-Project overhead and normal profit, and shall be as follows, subject to adjustment as provided in Subparagraph 9.1.1:

(State whether a stipulated sum or other basis. If a stipulated sum, state what portion of the sum shall be payable each month.)

9.1.3 ADJUSTMENT IN THE DESIGNER'S FEE Adjustment in the Designer's Fee shall be made as follows:

9.1.3.1 for changes in the Designer's Services, the Designer's Fee shall be adjusted as follows:

9.1.3.2 for delays in the Project not caused by the Designer, there shall be an equitable adjustment in the Designer's Fee to compensate the Designer for increased expenses.

\subsection{ADDITIONAL SERVICES AND REIMBURSABLE EXPENSES}

9.2.1 The Designer shall be compensated for Additional Services as mutually agreed upon by the Designer and Management Group on the following basis: 


\section{ARTICLE 10 CONSTRUCTOR'S COMPENSATION}

10.1 The Owner shall compensate the Constructor for Work performed on the following basis:

10.1.1 for Preconstruction Services, as follows:

(State whether a stipulated sum, actual cost, or other basis. If a stipulated sum, state what portion of the sum shall be payable each month).

10.1.2 the Cost of the Work as allowed in Article 17; and

10.1.3 the Constructor's Fee paid in proportion to the Work performed subject to adjustment as provided in Paragraph 10.4 .

10.2 The compensation to be paid shall be limited to the PTCE established in Amendment No. 1, as the PTCE may be adjusted and subject to the incentive and risk sharing provisions of Article 11.

10.3 CONSTRUCTOR'S FEE The Constructor's Fee shall be comprised of normal, non-Project overhead and normal profit, and shall be as follows, subject to adjustment as provided in Paragraph 10.4:

(State whether a stipulated sum or other basis. If a stipulated sum, state what portion of the sum shall be payable each month.)

10.4 ADJUSTMENT IN THE CONSTRUCTOR'S FEE Adjustment in the Constructor's Fee shall be made as follows:

10.4.1 for changes in the Work as provided in Article 20, the Constructor's Fee shall be adjusted as follows:

10.4.2 for delays in the Work not caused by the Constructor, provided in Paragraph 15.6, there shall be an equitable adjustment in the Constructor's Fee to compensate the Constructor for increased expenses; and

10.4.3 if the Constructor is placed in charge of managing the replacement of an insured or uninsured loss, the Constructor shall be paid an additional fee in the same proportion that the Constructor's Fee bears to the estimated Cost of the Work for the replacement.

\section{ARTICLE 11 \\ INCENTIVES AND RISK SHARING}

11.1 GOAL Owner, Designer and Constructor believe that by forming the CPD Team and implementing Collaborative Project Delivery, wasted cost and time will be eliminated from the design and construction process, the quality of the final product will be improved, and the project will be safer, all while increasing the return on investment for CPD Team Members.

11.2 FINANCIAL INCENTIVE PROGRAM In support of Collaborative Project Delivery, the Management Group shall develop a financial incentive program to encourage superior performance based upon Owner's Collaborative Project Delivery goals and to reward the CPD Team for successfully achieving superior performance and successfully exceeding the project expectations and benchmarks. The method, manner, amounts and timing of any payments made as a result of the financial incentives program shall be detailed and specified in an amendment to this Agreement.

11.3 Characteristics of Program Any incentive program should provide a basis for continually monitoring and reviewing the project team's performance, providing the team with periodic performance information to allow corrections or modifications during project performance to improve the quality of the services provided. The program should be funded with project savings as evidenced by contingency preservation and reduction in the 
Project's Costs of the Work as compared to the amounts contained within the PTCE. The program should consider performance in the following areas: cost, quality, safety, schedule, planning system reliability, innovative design, construction processes and teamwork.

11.4 SAVINGS To the extent the actual cost of the Project is less than the PTCE, the Parties shall share in such savings on the following basis:

(Indicate agreed upon percentages or other basis for sharing).

11.5 LOSSES In the event the actual cost of the Project exceeds the PTCE, such costs: (Indicate

applicable Loss Allocation approach):

.1 Shall be borne by the Owner.

- 2 Shall be shared by the Parties on the following basis (Indicate agreed upon percentages or other basis for sharing):

11.6 LOSS LIMITS To the extent the Parties elect to share costs in excess of the PTCE in accordance with Subparagraph 11.5.2, the Designer's and Constructor's Fees, as defined in Subparagraph 9.1.2 and Paragraph 10.3 ,

$$
\text { _ are not (select one) }
$$

at risk and the total amount of each Fee

shall

_ shall not (select one)

represent the Designer's and Constructor's limit of liability for losses apportioned pursuant to Paragraph 11.5.

\section{ARTICLE 12 \\ TRADE CONTRACTORS SUBCONTRACTORS, SUPPLIERS AND DESIGN CONSULTANTS}

12.1 PARTICIPATION IN COLLABORATION The Constructor may contract with key Trade Contractors and Suppliers during early Project design to provide preconstruction services and facilitate an integrated, collaborative design process, subject to the approval of the Management Group. Approved Trade Contractors and Suppliers shall sign Joining Agreements, as they become members of the CPD Team, accepting the principles and methods of collaboration set forth in this Agreement. A Trade Contractor may continue to serve as a Subcontractor during construction when the Management Group determines that its performance merits continued participation and accepts its price proposal. Approved Trade Contractors, Subcontractors and Suppliers shall contract directly with the Constructor.

12.2 SOLICITATION AND SELECTION The Constructor shall develop Trade Contractor, Subcontractor and Supplier interest in the Project and, in collaboration with the Management Group, develop a list of potential Trade Contractors, Subcontractors and Suppliers from whom proposals will be requested. Proposed Trade Contractors, Subcontractors and Suppliers must possess the qualifications, experience and financial resources to complete the work for which they are being proposed. The Management Group's approval of the inclusion of any Trade Contractor, Subcontractor or Supplier on the list of potential participants shall not constitute a waiver of the right of the Management Group later to object to or reject any proposed Trade Contractor, Subcontractor or Supplier.

12.3 SELF-PERFORMED WORK If Constructor proposes to self-perform a particular scope of work, it shall provide the Management Group with its qualifications to perform the work. If requested by the Management Group, Constructor may need to obtain at least two bona fide price proposals for work that is proposed to be selfperformed. 
22.5.1 Upon seven (7) Days' written notice to the Owner, the Constructor or Designer may terminate this Agreement if the Work has been stopped for a thirty (30) Day period through no fault of the Constructor or Designer for any of the following reasons:

22.5.1.1 under court order or order of other governmental authorities having jurisdiction;

22.5.1.2 as a result of the declaration of a national emergency or other governmental act during which, through no act or fault of the Constructor or Designer, materials are not available; or

22.5.1.3 suspension by Owner for convenience pursuant to Paragraph 22.1

22.5.2 In addition, upon seven (7) Days' written notice to the Owner, the Constructor or Designer may terminate the Agreement if the Owner:

22.5.2.1 assigns this Agreement over the Constructor's or Designer's reasonable objection, or

22.5.2.2 fails to pay the Constructor or Designer in accordance with this Agreement, or

22.5.2.3 otherwise materially breaches this Agreement.

22.5.3 Upon termination by the Constructor or Designer in accordance with Paragraph 22.5, the Constructor or Designer shall be entitled to recover from the Owner payment for all Work executed and for any proven loss, cost or expense in connection with the Work, including all demobilization costs plus reasonable overhead and profit on Work not performed.

22.6 OBLIGATIONS ARISING BEFORE TERMINATION Even after termination pursuant to Article 22, the provisions of this Agreement still apply to any Work performed, payments made, events occurring, costs charged or incurred or obligations arising before the termination date.

\section{ARTICLE 23 DISPUTE RESOLUTION}

23.1 WORK CONTINUANCE AND PAYMENT Unless otherwise agreed in writing, the Constructor or Designer shall continue the Work or Services and maintain the Schedule of the Work during any dispute resolution proceedings. If the Constructor or Designer continues to perform, the Owner shall continue to make payments in accordance with this Agreement.

23.2 DIRECT DISCUSSIONS If the Parties cannot reach resolution on a matter relating to or arising out of the Agreement, the Parties shall endeavor to reach resolution through good faith direct discussions between the Parties' representatives, who shall possess the necessary authority to resolve such matter and who shall record the date of first discussions. If the Parties' representatives are not able to resolve such matter within five (5) business Days of the date of first discussion, the dispute shall be submitted to the Management Group at its next meeting or at a special meeting requested by any Party. The Management Group shall review the dispute and take one or more of the following actions: (1) request additional supporting data from the claimant or a response with supporting data from the other Party, (2) request a technical analysis of the dispute from any CPD Team member; (3) proceed in an effort to achieve a negotiated resolution of the dispute. The Management Group may, but shall not be obligated to, consult with or seek information from either Party or from persons with special knowledge or expertise who may assist the Management Group in issuing a technical interpretation or recommendation, or in providing a root cause assessment, the cost of which shall be allocated by the Management Group. If the dispute remains unresolved after submission to the Management Group, the Parties shall submit such matter to the dispute mitigation and dispute resolution procedures selected herein.

23.3 MITIGATION If the Parties select one of the dispute mitigation procedures provided in this Paragraph 23.3, disputes remaining unresolved after direct discussions shall be directed to the selected mitigation procedure. The 
dispute mitigation procedure shall result in a nonbinding finding on the matter, which may be introduced as evidence at a subsequent binding adjudication of the matter, as designated in Paragraph 23.5. The Parties agree that the dispute mitigation procedure shall be: (Select only one)

_Project Neutral, or

_. Dispute Review Board

23.3.1 MITIGATION PROCEDURES The Project Neutral/Dispute Review Board shall be mutually selected and appointed by the Parties and shall execute a retainer agreement with the Parties establishing the scope of the Project Neutral's/Dispute Review Board's responsibilities. The costs and expenses of the Project Neutral/Dispute Review Board shall be shared equally by the Parties. The Project Neutral/Dispute Review Board shall be available to either Party, upon request, throughout the course of the Project, and shall make regular visits to the Project so as to maintain an up-to-date understanding of the Project progress and issues and to enable the Project Neutral/Dispute Review Board to address matters in dispute between the Parties promptly and knowledgeably. The Project Neutral/Dispute Review Board shall issue nonbinding findings within five (5) business Days of referral of the matter to the Project Neutral/Dispute Review Board, unless good cause is shown.

23.3.2 If the matter remains unresolved following the issuance of the nonbinding finding by the mitigation procedure or if the Project Neutral/Dispute Review Board fails to issue nonbinding findings within five (5) business Days of the referral, the Parties shall submit the matter to the binding dispute resolution procedure designated in Paragraph 23.5.

23.4 MEDIATION If direct discussions pursuant to Paragraph 23.2 do not result in resolution of the matter and no dispute mitigation procedure is selected under Paragraph 23.3, the Parties shall endeavor to resolve the matter by mediation through the current Construction Industry Mediation Rules of the American Arbitration Association, or the Parties may mutually agree to select another set of mediation rules. The administration of the mediation shall be as mutually agreed by the Parties. The mediation shall be convened within thirty $(30)$ business Days of the matter first being discussed and shall conclude within forty-five (45) business Days of the matter being first discussed. Either Party may terminate the mediation at any time after the first session, but the decision to terminate shall be delivered in person by the terminating Party to the non-terminating Party and to the mediator. The costs of the mediation shall by shared equally by the Parties.

23.5 BINDING DISPUTE RESOLUTION If the matter is unresolved after submission of the matter to a mitigation procedure or to mediation, the Parties shall submit the matter to the binding dispute resolution procedure designated herein: (Designate only one)

Arbitration using the current Construction Industry Arbitration Rules of the American Arbitration Association or the Parties may mutually agree to select another set of arbitration rules. The administration of the arbitration shall be as mutually agreed by the Parties. Project.

Litigation in either the state or federal court having jurisdiction of the matter in the location of the

23.5.1 The costs of any binding dispute resolution procedures shall be borne by the non-prevailing Party.

23.5.2 VENUE The venue of any binding dispute resolution procedure shall be the location of the Project, unless the Parties agree on a mutually convenient location.

23.6 LIEN RIGHTS Nothing in this Article 23 shall limit any rights or remedies not expressly waived by the Constructor that the Constructor may have under lien laws. 


\section{APPENDIX H \\ Bond Project \\ Martinez Unified School District}

Mr. Bruce Leslie, a part time consultant, hired by Martinez Unified (MUSD) to oversee the $\$ 45$ million bond issue from 2010 wrote on March 19, 2014 with a detailed description of the projects in their Phase 1 of modernizations under the 2010 bond issue.

The schools who have passed bonds, carefully watch all expenditures under the bond issues. For example, the Official in charge of the District's facilities, Andi Stubbs, asked Mr. Leslie to reply to my inquiries, on the condition that the reply wouldn't generate any additional billing to the District. Mr. Leslie replied with an informative letter, copied below.

Good afternoon John.

My name is Bruce Leslie and I am the Bond Project Coordinator for the Martinez Unified School District. I have not been able to respond to your phone message or other email request for information due to my limited work schedule. I am a $50 \%$ employee and as such only working one day per week currently. I was hired last May 1, 2013 , to fill the open position of Bond Project Coordinator at that time.

My supervisor is Andi Stubbs, CBO for the Martinez Unified School District. She is also the Facility Director for the district. Jon Novero , RGM and Associates, is our Construction Manager. Together, we are the main components of the Bond Team for the district.

I listened to your message last evening before the School Board meeting and understand that you are a graduate student working on your thesis about School modernization with an emphasis on the funding mechanism for these projects. You asked about the Lease/Leaseback funding process in particular.

To answer your immediate question, yes we are currently using the Lease/Leaseback funding process to complete our current projects. Measure K, a \$45 million general obligation facilities bond approved by local Martinez voters, was passed on November 2, 2010. There is a Citizen Oversight Committee as required by the Bond structure.

The School Board determined that the projects would be done in Phases, after determining the most important needs first and following the Measure $\mathrm{K}$ bond language. Here is a list of the completed Phase 1 projects ( \$25 million ) : 
Installation of energy management controls; Solar power generation through-out; IT upgrades; VOIP systems through -out the district; a parking lot/drop-off safety project/ kitchen remodel at Las Juntas Elementary; addition to the Alhambra High School ( AHS ) Performing Arts building; renovation/modernization of the AHS central plant; renovated softball field at AHS and a new Alternative High school campus. This last project, the Vicente Alternative High School/Briones School project, is the last of the Phase 1 projects. It is just getting started with a completion date of this Fall 2014.

The School Board just approved the sale of the final $\$ 20$ million bonds for the Phase 2 projects in November 2013. The Board is re-evaluating the current Phase 2 project list generated 3 years ago to make sure that it reflects the most current needs of our District.

My knowledge of the L/LB method of funding projects is limited but I know that this method provides the District with the legally approved means to control costs while providing the District with the best usage of their limited funds. We have enjoyed great success using the L/LB method and plan on continuing to use it in the future as needed for our Phase 2 projects.

I hope that you find this information helpful.

Respectfully,

Bruce Leslie

Bond Project Coordinator

MUSD 